\title{
Ticket Splitting in a Nationalized Era
}

\author{
Shiro Kuriwaki*
}

March 2023

\begin{abstract}
Party loyalty in U.S. Congressional elections has reached heights unprecedented in the post-war era. Theories of partisanship as informational cues would predict that ticket splitting from national partisanship should be even more rare in lowinformation elections. Yet, here I show that ticket splitting in state and local offices is often higher than in Congress. I use cast vote records from voting machines that overcome ecological inference challenges, and develop a clustering algorithm to summarize such ballot data. For example, about a third of South Carolina Trump voters form a bloc whose probability of ticket splitting is 5 percent for Congress, but 32 percent for county council and 50 percent for sheriff. I show that a model with candidate quality differentials can explain these patterns: Even in a nationalized era, some voters cross party lines to vote for the more experienced and higher quality candidate in state and local elections.
\end{abstract}

* Assistant Professor, Department of Political Science, Yale University (Website: www . shirokuriwaki.com).

* I thank Duncan Buell, Jeff Lewis, Stephen Pettigrew, and Charles Stewart for their expertise in cast vote records; Carolyn Abott, Alexander Agadjanian, Yuki Atsusaka, Peter Buisseret, Justin de Benedictis Kessner, Barry Burden, Hanno Hilbig, David Kimball, Edward Lawson, Jr., Daniel Moskowitz, Socorro Puy, Clémence Tricaud, Chris Warshaw, Soichiro Yamauchi, Hye Young You, Michael Zoorob, members of the Imai Research Group, members of the Democracy Policy Lab at Stanford, and others for their comments and feedback; Eric Leubner for research assistance; Kevin DeLuca for sharing his candidate quality data; Jonathan Robinson for sharing Maryland cast vote records; and to Steve Ansolabehere, Matt Blackwell, Kosuke Imai, and Jim Snyder for their guidance. An earlier version of this paper was titled "Party Loyalty on the Long Ballot: Is Ticket Splitting More Prevalent in State and Local Elections?" This project was financially supported by the MIT Election and Data Science Lab. 
The nationalization of voter behavior in recent decades is thought to have shifted the electoral landscape, changing the conventional wisdom about the U.S. electorate. More people vote for the same party's candidates in races for President and the U.S. House Representatives, or for U.S. Senator and Governor, than at any other point in the post-war era (Jacobson 2015; Sievert and McKee 2018). But almost all of the evidence in accounts of nationalization comes from congressional and gubernatorial contests, and not from down-ballot state and local elections.

The consequences of nationalization are of particular concern in state and local elections. Constituents in a federal system can elect state and local representatives separately from national ones, and can therefore split their ticket, i.e., vote for a candidate of party $A$ in one office but vote for a candidate of party $B$ in another. But under a thoroughly nationalized politics, these constituents would vote only for one party — regardless of differences in candidates' relevant experience or the duties of each office. As Hopkins (2018) warns, party loyalty gone too far turns into blind partisanship and dampens electoral accountability. Is ticket splitting more prevalent in races for state legislature, sheriff, or county council than they are in the evidently nationalized offices of Congress?

This study is the first analysis, to my knowledge, of individual ticket splitting in state and local offices directly compared with ticket splitting in national offices. I find that a voter often ticket splits more in state and local offices than in congressional offices. Importantly, I show that this ticket splitting is systematic: it tends to advantage the incumbent, the candidate with more campaign finance contributions or newspaper coverage, and candidates who are of higher quality (as inferred from newspaper endorsements).

The fact that ticket splitting exists at all during a time of nationalized politics might surprise some readers. Existing literature finds nationalizing trends in gubernatorial elections (Sievert and McKee 2018; Amlani and Algara 2021), state legislative elections (Rogers 2023), and public opinion (Tausanovitch and Warshaw 2014), which would lead us to speculate that local politics has also nationalized. Moreover, theories of partisanship as an informational heuristic would predict that blind partisan voting would be more prevalent in low-information contests like state and local races where information about the election is scant (Peterson 2017; Moskowitz 2020). However, what 
these predictions fail to take into account is the possibility that other candidate-based factors in state and local offices could be large enough to counteract straight ticket voting. In a spatial model of vote choice, the probability of ticket splitting is increasing in a candidate's advantage on valence characteristics, i.e., aspects such as candidate experience, effort, and capability that all voters prefer more to less. If voters can recognize and care about these attributes when they vote, they may split their ticket for the candidate with a valence advantage. In contrast, if there is either no information about candidate's valence when voters vote, or voters do not value candidate quality relative to copartisanship, the model would predict no ticket splitting.

Ticket splitting is well-studied in Congress, but the existing literature is at best only suggestive when it comes to state and local politics. For many state and local offices, the literature provides no estimate of ticket splitting. This is because existing work relies on aggregate election returns that suffer from the ecological inference problem (Trounstine 2018) or limited survey samples where vote recall is measured with error (Beck et al. 1992). Virtually all of these studies also only examine one subset of offices on the ballot at a time. In a review of the literature on local elections and representation, Warshaw (2019) calls for "much more survey evidence on local elections than there currently exists" to understand vote choice in state and local elections.

This study departs from traditional measurement approaches by collecting cast vote records. Cast vote records are complete records of an individual voter's official vote choice on the entire long ballot, produced by the voting machine and handled by election administrators. I reconstruct the ballot layouts from South Carolina voting machines for five general elections between 2010-2018. I complement this analysis with an additional 12 million ballots from Maryland, Maricopa County, Arizona, and Palm Beach County, Florida. My data, measuring vote choice without measurement error, reveal patterns of voting behavior that have been not possible to measure in existing surveys and election returns. My dataset improves upon past studies of cast vote records, which study only several counties in a single year (Gerber and Lewis 2004; Bafumi et al. 2012; Hansen 2015). These individual records of actual vote choice, free of measurement error, are especially illuminating for offices where currently no survey-based measure of ticket splitting exists. These include state 
legislatures, county councils, and sheriffs.

I present my main findings in two parts. In the first, I provide a summary of ticket splitting by office. About 5 percent of South Carolina voters split their ticket in Congress, while ticket splitting rates range from 9 to 17 percent in state and local offices. However, the ubiquity of unconstested races in these offices makes it inappropriate to infer individual voting patterns from naive cross-office comparisons. I therefore design a clustering algorithm with a modeling innovation that addresses such spottiness. Applying this method to the South Carolina ballots, I show that over a third of 2016 voters can be classified as a swing voter bloc, with a 20 to 50 percent probability of splitting their ticket from their Presidential vote of Donald Trump or Hilary Clinton. These voters are more likely to split their ticket in state and local offices than in congressional ones.

The second part explains these patterns by showing that measures of candidate quality such as incumbency, coverage in the news, fundraising, and newspaper endorsements are all positively associated with ticket splitting. I show using the same data that, first, more voters defect from their national party loyalty when their copartisan candidate is challenging an incumbent. Further analysis shows that the same pattern holds for candidates with more newspaper coverage or campaign fundraising. Finally, ticket splitting positively correlates with candidate quality inferred from historical newspaper endorsements (DeLuca 2022). All this suggests that a significant component of ticket splitting is candidate quality or relevant experience. In light of my model, I interpret this finding as evidence that contemporary voters both know and care about quality differences between candidates in state and local elections. These are low-information offices, but there still is a signal that distinguishes candidates within an office.

In summary, this study reveals the previously unmeasured structure of vote choice in state and local contests, and offers a model for ticket splitting that holds even in an era where candidates' positions have nationalized. The partisan ballot is a central feature of American Politics that links national politics with state and local policy. With the aid of cast vote records, I show that state and local candidates with more experience net a substantial amount of votes from opposing partisans, not unlike the congressional candidates of a less nationalized era. 


\section{Ticket Splitting in a Nationalized Era}

In the 2018 general election for Governor in South Carolina, the Republican candidate Henry McMaster won all 30 counties that President Donald Trump won in 2016, and only flipped one out of 16 counties won by Hilary Clinton. McMaster's and Trump's county-level two-party voteshare were correlated at 0.99 (Hopkins 2018; Amlani and Algara 2021). The correlation between the 1970 Governor's voteshare and the 1968 Presidential voteshare, in contrast, was 0.40. Accounts of nationalization, most comprehensively documented by Hopkins (2018), explains trends like these where the partisan geography of a Governor's votes became almost indistinguishable from those for President or Congress. The theory of nationalization argues that as parties polarized in Congress, the platforms of state parties became more similar to national party positions, and voters began to identify with the Republican or Democratic party undifferentiated by the level of government in question. In the next section, I provide a model that connects nationalization and ticket splitting.

The nationalization of elections is well-documented in U.S. House races (Jacobson 2015, 2021), but how these trends play out in state and local elections is not well understood. Nationalization of Congress might bleed into nationalization of these offices, given that the U.S. elections often directly elect these representatives in the same ballot as national offices, only displaying candidate's party affiliation on the ballot. Historical state legislative election returns suggest increasing nationalization, though not to the same extent as in Congress, for state house races (Rogers 2017, 2023). However, as I explain after the theoretical framework, both aggregate and survey evidence for these offices suffer from measurement issues inherent in the type of data they use. Evidence for local offices such as sheriff, county councils, and mayors is even more limited.

\section{A Theoretical Framework for Ticket Splitting}

A spatial voting model can help enumerate the reasons why a voter would split their ticket. According to this framework, ticket splitting does not only decline with nationalization, but is shaped by the combination of polarization and candidate quality differences. 
In a canonical spatial model, citizens choose the candidate whose policy position is closest to them on an ideological spectrum. Voting on the long ballot is akin to a citizen making a series of choices between candidates of two parties. If all Republican candidates for these choices held identical policy positions with each other, and all Democratic candidates held another set of identical positions, a voter would cast a straight ticket vote. This setting exemplifies nationalized politics: co-partisan candidates for local and national office run on identical platforms and voters vote accordingly for a party slate. I set up this model in Appendix A.

There are at least three classes of explanations for why a voter might split their ticket in this framework. First, voters could cross party lines in races where the candidates are less polarized. This is the simplest explanation, because it operates within a single issue dimension. A second explanation for ticket splitting posits that state and local politics is contested over a second issue dimension. Local politics revolves around contestation over issues specific to that locality (Oliver, Ha, and Callen 2012), and voter's preferences over those debates over municipal policy often do not perfectly correlate with their partisanship (Jensen et al. 2021). Such a setting can generate ticket splitting if candidates compete over local issues (Besley and Coate 2008). For example, suppose elections for local office feature candidates that all take the same stances on the environment, while Republican and Democratic candidates for national office take opposing stances. Then environmentally conscious voters would vote for a single party within national offices but then feel free to split their ticket in local offices. The evidence of candidate convergence among sheriff's policies suggests an analogous dynamic (Thompson 2019).

The third reason voters may split their ticket, the one I focus on in this study, is that voters care about candidate quality and one candidate has a quality advantage over his opponent. I use the formal and broader term of valence to refer to such qualities. Valence is an attribute that all voters prefer more of to less, such as candidate competence, effort, or experience for the job. ${ }^{1}$ As I show formally in Appendix A, the main insight from spatial models with valence is that ticket splitting

1 Furthermore, I show that more informational certainty around a candidate's policy position in my model effectively constitutes as a valence advantage as well. In this sense, candidate visibility, or salience, is captured within the concept of valence. 
for a candidate would be increasing in the ratio of the candidates' valence advantage relative to the candidate's spatial distance. Therefore, even when state and local candidates have polarized and nationalized, ticket splitting can occur if there are differences in candidate quality in those offices.

The model of valence connects ticket splitting with the local politics literature, and is consistent with earlier findings about ticket splitting. Using incumbency as a measure of positive valence is a natural choice in state and local politics: regression discontinuity designs have found that the effect of incumbency on staying in office the next election to be as large as 20-30 percentage points in city council, mayoral, and sheriff elections (Trounstine 2011; de Benedictis-Kessner 2017; Warshaw 2019; Zoorob 2022). Past work on ticket splitting also lends support for the model that the higher quality candidate nets more by voters splitting their ticket. Beck et al. (1992) showed that highly visible statewide candidates draw more split ticket voting, and Burden and Kimball (2002) showed that congressional candidates with larger campaign expenditures appear to compel more voters to split their ticket. However, disentangling the effect of quality, scare-off, and advantages that accrue from governing is challenging (Eggers 2017).

Information is crucial in these valence-based accounts. A candidate's valence advantage cannot factor into voter's decisions if that informational signal fails to reach voters before they vote. In all but three U.S. states, ballots do not contain anything other than the candidate's name and party. ${ }^{2}$ That is why the literature on media and information may lead one to predict more straight ticket voting in low-salience elections (Darr, Hitt, and Dunaway 2018; Moskowitz 2020; Djourelova, Durante, and Martin 2021). Peterson (2017) finds that the lack of candidate-specific information increases the likelihood that voters vote straight ticket, at least for congressional races. Accordingly, many researchers of nationalization suggest that the decline of local news accelerated this trend (Hopkins 2018). Moskowitz (2020) finds that the decline in the supply of news related to state government leads to a decline in ticket splitting for state offices such as Senate and Governor.

One explanation that does not cleanly fit in my formal model is the possibility that split their ticket in order to balance the partisanship (Burden and Jones 2009). Voters might strategically vote

2 The exceptions, as of 2018, are California, Georgia, and Massachusetts, based on the samples acquired by Ballotpedia. https://perma.cc/8ADA-B5YT. 
for a Republican Congress to serve as a check on a Democratic President, for example. While Congress and the Presidency are part of one veto bargaining process, it is unclear how this balancing logic plays out between local and national offices, which are not part of the same legislative process.

In this study, I test the valence hypothesis primarily for theoretical clarity, as well as to show how ticket splitting could occur even when candidates have, as conventional wisdom goes, nationalized. Multiple issue dimensions could explain remaining variation. But spatial models with multiple issue dimensions are notoriously intractable, so their theoretical predictions are less clear. And while moderation may be a factor, the valence explanation is the one could explain ticket splitting even if all candidates were nationalized and polarized. ${ }^{3}$

\section{Limitations to Existing Studies and Traditional Measures}

Existing studies almost exclusively rely on two types of data to measure ticket splitting: aggregated election returns and survey samples measuring self-reported vote choice. The use of election returns dates at least back to V.O. Key's chapter in his treatise of state politics, "The Lottery of the Long Ballot" (Key 1963, ch.7) and continues to be used in recent work (Trounstine 2018; Djourelova, Durante, and Martin 2021). However, comparisons across voteshares are only suggestive of voting patterns on the long ballot. In the simplest case of voters voting for two offices each with only two candidates, the commonly-used difference in candidate voteshares underestimates the prevalence of ticket splitting by an unknown amount. ${ }^{4}$ This is because a difference in voteshares only measures net ticket splitting, canceling out two types of split ticket voters who split for opposing candidates. Once we include the possibility that voters can roll-off or vote for a third party candidate, this measure can also overestimate ticket splitting. Social scientists have developed ecological inference methods to get around this problem. These methods estimate the joint probabilities of voting on the long ballot that best comports with aggregated returns, subject to accounting constraints and modeling

3 Testing the moderation hypothesis is also complicated by the fact that candidate positioning is likely endogenous to their valence advantage (Groseclose 2007).

4 For an example of this measure, see Darr, Hitt, and Dunaway (2018). For usage in the popular press, see FiveThirtyEight, "Split-Ticket Voting Hit a New Low in 2018 Senate and Governor Races" (November 19, 2018). https: //perma.cc/9Y75-3J9R. 
assumptions (King 1997; Wakefield 2004). Burden and Kimball (2002) were one of the first to apply ecological inference techniques to election returns and estimate the degree of ticket splitting between votes for U.S. House and President. As developed as these methods are, they are inherently model-based inferences. Their output may be biased and the opportunity to quantify the direction of that bias is rare.

Surveys circumvent the aggregation problem by sampling individuals and prompting them to self-report their vote choice. They are the central piece of evidence documenting the rise of straight ticket voting and uncovering its mechanisms (Jacobson 2015; Abramowitz and Webster 2016; Davis and Mason 2016). But when studying state and local elections, surveys become prohibitive for measuring any type of vote choice due to two limitations. The first is measurement error through misreporting. Surveys require voters to either recognize the names of the candidates they will vote for in advance of the election, or recall which candidates they voted for several days after. With a ballot that can range from 10 to 20 names in a general election, this process can be fraught with error. For example, in the 2018 Cooperative Congressional Election Study (CCES), a staggering 86 percent of the respondents in South Carolina reported voting for the "Democratic candidate" or "Republican candidate" in state senate even though there was no state senate race in South Carolina that year $(n=607)$. Only 9 percent correctly reported that "there was no race for this office."

The second limitation is simply that very few surveys poll on state and local races. Beck et al. (1992) is the only published study, to my knowledge, that polled statewide offices such as Attorney General by name, and Arceneaux (2006) reports that there were only three cities in the November 2002 election for which the U.S. Senate, Governor, and mayor were on the same ballot. Moreover, sample sizes for these two studies were limited to around 500 and 1,200. In summary, despite the centrality of ticket splitting to assess nationalization, past work has struggled to measure ticket splitting in the offices that stand to change the most drastically from nationalization, such as sheriff and councy council (Farris and Holman 2017; de Benedictis-Kessner and Warshaw 2020). 


\section{Data and Case Selection}

The ideal methodological approach is one that drills down each individual's long ballot, observing the entire series of vote choices across offices. Fortunately, cast vote records do precisely that. I first show how these records compare to traditional data sources. I then introduce the cast vote records in four states, focusing on those in South Carolina.

\section{Cast Vote Records for Measuring Ticket Splitting}

Cast vote records (also referred to as ballot image logs) are complete readouts from voting machines. Ballots in the U.S. are either paper-based or electronic (referred to as Direct-Recording Electronic, or DRE). DRE machines record each vote as it is cast through a touchscreen. Ballot anonymity ensures that these records are de-linked with the identity of the voter from the outset. While not a part of routine election reporting, as a technical matter cast vote record information is retrievable from the DRE software. Jurisdictions sometimes choose to release these records as public record for post-election audits. Recently, cast vote records have become salient in the controversies over election integrity. ${ }^{5}$

Cast vote records have distinct advantages in measuring electoral behavior over three alternative data sources: aggregate election returns, surveys, and voter files. As Table 1 summarizes, none of the three traditional sources can simultaneously provide data at the individual level and measure vote choice without sampling error, but cast vote records do. Cast vote records are not without their limitations. Demographic information from voter files cannot be linked to individual ballots to protect ballot secrecy. This precludes individual analyses of racial voting. Votes by the same person across separate elections are not linkable either. Yet, once they are formatted and linked to information about candidates, they are uniquely conducive to study vote choice across the long ballot.

The use of cast vote records in academic research is not new, but the few existing studies with

5 See for example ABC News, "With 10 weeks until midterms, election deniers are hampering some election preparations" (August 30, 2022). https://perma.cc/J9N9-6PY4. 
Table 1: Cast Vote Records Compared to Traditional Electoral Datasets

\begin{tabular}{rcccc}
\hline & $\begin{array}{c}\text { Cast Vote } \\
\text { Records }\end{array}$ & $\begin{array}{c}\text { Election } \\
\text { Returns }\end{array}$ & Surveys & $\begin{array}{c}\text { Voter } \\
\text { Files }\end{array}$ \\
\hline Individual level? & $\checkmark$ & & $\checkmark$ & $\checkmark$ \\
Vote choice observed? & $\checkmark$ & $\checkmark$ & $\checkmark+$ error & \\
Covers all offices on the ballot? & $\checkmark$ & $\checkmark$ & & \\
Personally identifiable information? & & & Imperfect & $\checkmark$ \\
Contains precinct identifier? & $\checkmark$ & $\checkmark$ & & $\checkmark$ \\
\hline
\end{tabular}

Note: Each column lists the properties of a type of major election dataset.

this data have not attempted to describe the patterns of vote choice in state and local contests. Past studies have used the data to summarize ranked choice voting patterns (Alvarez, Hall, and Levin 2018), establish the degree of partisan voting in a referendum (Morse 2021), and validate ecological inference methods (Park, Hanmer, and Biggers 2014). Past studies most similar to the current study use cast vote records to estimate latent preferences. Gerber and Lewis (2004) use ballot images from Los Angeles county in one election to estimate voter ideal points. Later Herron and Lewis (2007) analyzed ballot images from ten Florida counties from the 2000 presidential election to estimate the ideal points of Ralph Nader voters. All of these past studies use cast vote records only in a subset of counties in a state, in a single year.

Cast vote records are most powerful for making within-person, across-office comparisons of vote choice. However, a subtle barrier is the prevalence of districts where the choice set of votes varies due to lack of two-party contestation. I therefore design a clustering algorithm, available as open-source software clusterCVR, to summarize this data and make cross-office comparisons within a bloc of voters. This methodological approach, which I describe further in presenting results, is another way in which my approach differs from existing use of cast vote records. ${ }^{6}$

6 Ideal points, as used in Herron and Lewis (2007) and Gerber and Lewis (2004), impose a spatial model of vote choice that may be may be less appropriate for voters' preferences across a few offices than it is for legislators' rollcall votes (Broockman 2016). 


\section{Case Selection}

The main set of cast vote records for this study are 6.6 million ballots across five general elections in all of South Carolina. I also evaluate the generalizability of my results in about 9.6 million ballots across four elections in all of Maryland, a Democratic stronghold; 2.5 million ballots for the 2020 election in Maricopa County, Arizona, a swing state; and 0.3 million ballots from Palm Beach County, Florida, in 2000 using data from Herron and Lewis (2007).

I arrive at these cases from a search of cast vote records in all 50 states. Availability of cast vote records is limited, often only available through a public records request for a single election and each county (Morse 2021). Seven states centrally collect the cast vote records in a unified format (Kuriwaki 2020). Of these, only Maryland and South Carolina made the statewide cast vote records available. From 2005 to 2018, all counties in South Carolina used the iVotronic DRE voting machine manufactured by Election Systems and Software (ES \& S). Maricopa county (which contains the entire city of Phoenix) also administers a single format for its cast vote records. Appendix B.3 provides further details on the data collection across these states. These states offer a rare opportunity to study the long ballot because of the centralized and transparent election administration they run. South Carolina is most useful for this study than Maryland or Arizona, however, because the former contains more counties and therefore more county-level contests, providing candidate-level variation. Maryland has half as many counties as South Carolina while having a larger population statewide. I therefore use South Carolina as my primary dataset for analysis.

The South Carolina State Election Commission has made the cast vote records from these machines public from the 2010 general election onwards for their post-election audit. In 2010, a victory of a virtually unknown candidate in the state's Democratic primary for U.S. Senate led Buell et al. (2011) and Bafumi et al. (2012) to analyze the state's cast vote records through a public records request, prompting the practice of posting cast vote records. Samples of the iVotronic screen appear in Appendix B.2. The raw iVotronic cast vote records are not immediately useful because they are logs of the choices each voter cast, and the set of choices a voter chose from must be inferred by the analyst. I therefore reconstruct the ballot style by inferring which contests were up for election 
in each precinct combination from the set of votes cast. I then merge in candidate's party and campaign information. Details of these steps are left to Appendix B.1, and the details on the format of the cast vote records in the three other states in Appendix B.3. Through this procedure, I am able to capture how each election day voter voted on the full extent of their ballot (See Appendix C for a summary table).

\section{Comparability of State Politics in South Carolina}

South Carolina is comparable to other states in the number of elected offices on each voter's general election ballot. The state has 7 congressional districts, 124 state house districts, and 46 counties each with a county council often elected through single member districts. Statewide, Attorneys General, Secretaries of State, and superintendents are elected in conjunction with the Governor's race in midterm years. Countywide elections include the partisan offices of sheriff, county clerk, treasurer, and probate court judges. There are few off-cycle elections in South Carolina, so the general elections I analyze asks each voter to make choices for on average 18 offices in a midterm year and 11 offices in a presidential year. Partisan contests, i.e. contests where candidate's party affiliation is shown on the ballot, comprise about two thirds of these contests.

Existing research suggests that state legislatures, which deliberate on education spending, environmental regulation, abortion, and other issues, are as polarized as Congress. ${ }^{7}$ Other offices tend to focus on administrative matters (Oliver, Ha, and Callen 2012). County councils are legislative bodies that often discuss transportation infrastructure, public facilities, and sales taxes. Sheriffs are the chief law enforcement officer and manage county jails, auditors calculate millage rates, treasurers collects taxes and oversees the disbursement to other jurisdictions, and the clerk of court manages court dockets and manages the collection of fines and fees. In the judicial branch, circuit solicitors (known as district attorneys in other states) serve as the chief prosecutor of state government, and probate court judges have jurisdiction over civil cases such as estate inheritance. Despite

\footnotetext{
7 According to 1996-2009 legislator ideology estimates from Shor and McCarty (2011), the spatial gap between the median Democrat and median Republican South Carolina state legislator was about as large of the spatial gap between members of Congress. During 2012-2020 the gap in South Carolina grew 23 percent (Shor and McCarty 2022).
} 
their administrative functions, all of these offices are directly elected through partisan elections in general elections. Almost all candidates register for the Republican or Democratic party and win a party primary to be elected.

The available survey evidence suggests that straight ticket voting in South Carolina is comparable to the national average. Among the respondents in the CCES from 2010-2018 who voted for major party candidates in the state, 93 percent voted for the same party between the Presidency and the U.S. House $(n=3,610)$. This is within one percentage point of the national average $(n=$ 255,380). The CCES survey samples in Maricopa $(n=3,868)$ and Maryland $(n=5,342)$ are also close to the national average, with Maricopa's straight ticket vote being about two points higher and Maryland being a fraction of a point lower.

While the CCES does not measure ticket splitting in more down-ballot offices, another aspect of South Carolina ballots suggests that its straight ticket voting rate across offices may be uniformly higher than other states, making it a less likely case to find ticket splitting. South Carolina is one of six states in which voters have an option to automatically cast a straight ticket. ${ }^{8} \mathrm{~A}$ voter can either click through the entire touchscreen ballot, or he can select a party in the "Straight Ticket Party Option" (or party lever) that appears as the first question on every ballot (See Appendix B for an example). This auto-fills the voter's ballot to select that party's candidates for every applicable contest. These selections can be reversed case-by-case before the ballot is cast. Voters in other states whose ballots do not have this autofill option may, all else equal, split their tickets in more ways.

Finally, that South Carolina is a typical state with respect to ticket splitting may not comport with the state being a state in the Deep South. It is worth noting that Democrats win seats at considerable rates on the long ballot in this state. For example, just over half of all countywide executive offices elected on a partisan ballot in 2016-2018 were Democrats. The Republican party has controlled the governorship and the state legislature since 2003, but the same general election electorate has voted in a considerable number of Democrats in state and local offices, well after the critical elections associated with realignment and nationalization. Appendix $\mathrm{C}$ tabulates the result of nearly 10,000

8 The other states, as of 2022, are Alabama, Indiana, Kentucky, Oklahoma, and Utah. 
partisan contests in the state over the past four decades. That said, I discuss how the theoretical framework would generate predictions for data outside this context after presenting all results.

\section{Data on Candidates}

After measuring the prevalence of ticket splitting across the long ballot, I then combine this information with information about the candidates in each race. The ballots and official election results do not record candidate's incumbency. I therefore search old versions of county websites, where necessary, to mark the incumbency status of candidates in state and local office.

I collect three more measures of candidate quality that are available for open (i.e., non-incumbent) contests. First, I search a newspaper database that has ample coverage of state and local newspapers, and count the number of articles in South Carolina's 71 state newspapers that mention their full name during the term for that office. In total, this search accounts for 356,209 article hits across 764 candidate-election combinations. A detailed description of this search is left to Appendix B. Second, I also record the amounts each candidate raised during the election cycle from campaign finance data collected from the Federal Election Commission and the State Ethics Commission for

state and local offices (See Appendix B). News coverage correlates with name recognition, and the amount of campaign contributions a candidate raises proxies for candidate effort and candidate quality (Prat, Puglisi, and Snyder 2010).

Third, I use estimates of candidate quality as inferred from newspaper endorsements from DeLuca (2022), which I describe in the results. This measure is desirable because it is analogous to an expert-coded measure of quality, and covers state and local offices. I find that all three of these quality measures correlate with the ticket splitting in the same way.

\section{Party Loyalty on the Long Ballot}

To compare ticket splitting across offices, I pick one "top of the ticket office" and fix it as the reference office. In other words, I define ticket splitting for another office $j$ with the vote choice in office $j$ compared to that reference office. For my purposes, this office must be one that is common across 
all voters in an election and reasonably represents the voter's national party loyalty. In Presidential election years, the top of the ticket office is the President following previous studies. In midterm elections, I use the U.S. Senate election as the reference category when one is on the ballot. This is not the case in 2018 in South Carolina, so I use the Governor's election there instead. The patterns I show are robust to using the Governor as the reference category for all other midterms as well (2010, 2014).

I also limit my summary statistics to votes in contested races. A race is contested in my analysis if it is a single-member district with one Democratic and one Republican candidate. For example, if a contest features a Republican candidate, a Green party candidate, and a Libertarian candidate, I still count that as an uncontested race.

\section{Ticket Splitting Rates by Office}

If candidates were thoroughly nationalized and voters either did not know or did not value candidate quality, ticket splitting should be low across the entire ballot. However, across all states I examine, this is not the case.

Figure 1 shows the overall rate of split ticketting by office. In red are the rates of voting among "Republican" voters: those who voted for Romney, Trump, the Senate candidates DeMint or Graham, or in 2018 the Governor candidate Haley. In blue are "Democratic" voters who voted for Obama, Clinton, or the Democratic Senate or Governor candidates. The figure shows for example that among voters in contested U.S. House districts who voted for a Republican at the top of the ticket, only 5 percent voted for the Democrat and split their ticket. Figure D3 in the Appendix breaks down each statistic by election.

We see from these simple cross-comparisons that the ticket splitting rates in state and local office are often higher than in the U.S. House. ${ }^{9}$ Consistent with existing survey evidence (Jacobson 2021), the ticket splitting rate for the U.S. House hovers around 5 percent. In contrast, 17 percent

9 For comparisons with the U.S. Senate, see Figure D3. There is only one race where I can compare the Presidential to the U.S. Senate vote. In 2016, incumbent Senator Tim Scott (R), who is Black, ran for re-election against a Black Democrat. Fourteen percent of Hilary Clinton voters voted for Scott. I do not show this office in Figure 1 because this is only one contest. 


\section{Figure 1: Prevalence of Ticket Splitting by Office}

\section{Among voters of Republican} Top-of-ticket candidate

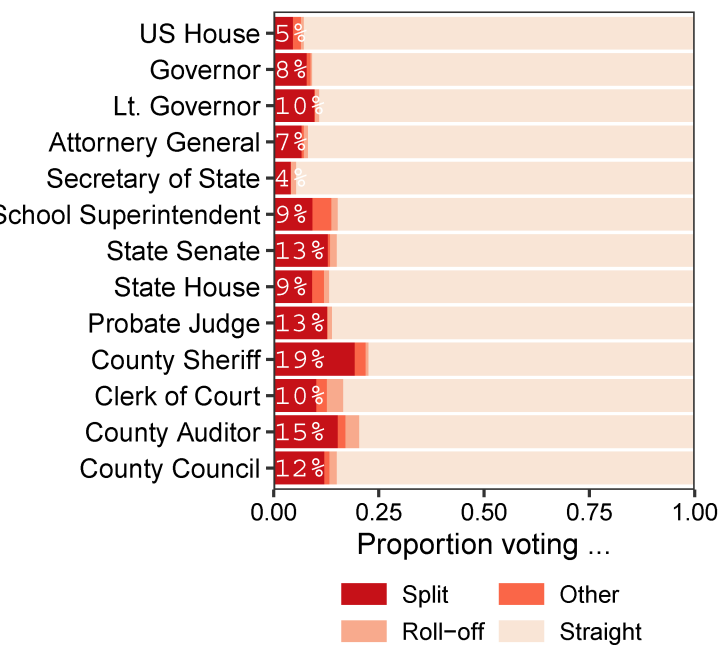

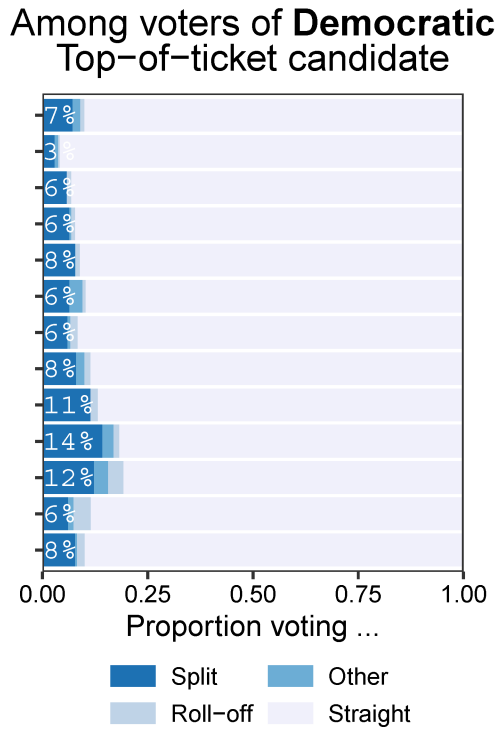

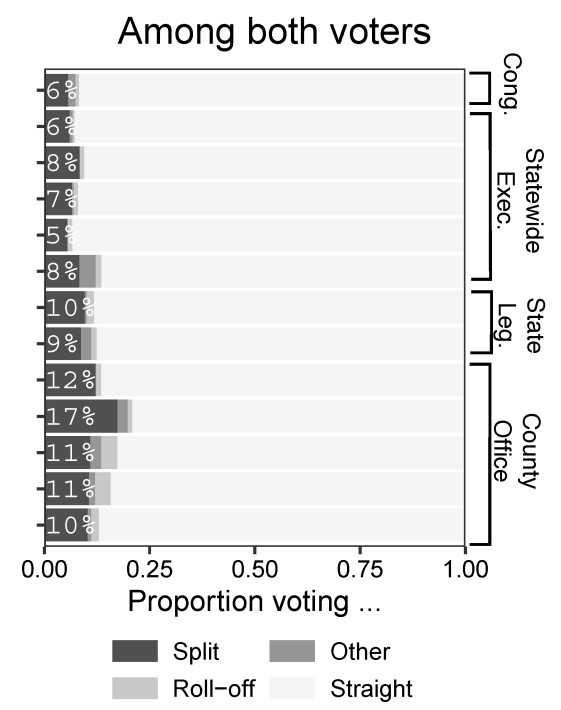

Note: Each bar marks the proportion of South Carolina votes for a party relative to a voter's vote for President (2016, 2020), U.S. Senate (2010, 2014), or Governor (2018). Red bars are proportions among voters who voted for a Republican, Blue bars among the Democrat, and Gray bars among both. Proportions are only computed among contested races. The sample sizes and proportions for each election year - office combination, as well as those from Maryland, Maricopa County, and Palm Beach County, are shown in Appendix D.

of two-party voters voting in contested Sheriff elections split their ticket.

I next summarize the data into interpretable blocs. As described earlier, a shortcoming of the simple comparison implied in Figure 1 is that it compares different subpopulations. In contrast, clustering is an attractive approach because it leverages the multidimensional nature of an individual's long ballot. It can do so even when there is no information about the individual other than their choices.

Formally, I posit that each voter $i$ belongs to one of $K$ clusters (where $K \geq 2$ is picked by the user), but that cluster membership $Z_{i}$ is unobserved. Instead we only observe a vector of $J$ choices $\mathbf{Y}_{i}=\left[Y_{i 1}, \ldots, Y_{i J}\right]$ for each voter: a straight ticket, split ticket, or abstain for each of the $J$ offices on the long ballot. In its simplest form, a clustering algorithm uses only the $[N \times J]$ matrix $\mathbf{Y}$ and a standard model of vote choice to estimate two quantities of interest: The overall prevalence of 
cluster $k$ :

$$
\pi_{k}=\operatorname{Pr}\left(Z_{i}=k\right), \text { where } \sum_{k=1}^{K} \pi_{k}=1,
$$

and the probability that a member of cluster $k$ votes for choice $\ell$ in office $j$ :

$$
\mu_{k j \ell}=\operatorname{Pr}\left(Y_{i j}=\ell \mid Z_{i}=k\right), \text { where } \sum_{\ell=1}^{L} \mu_{k j \ell}=1 \text {. }
$$

I derive a clustering algorithm designed around particular features of the ballot data. First, to account for abstentions and third party votes, outcomes are allowed to be unordered categorical variables. Second, unlike the closest model in the existing literature (Linzer and Lewis 2011), I account for the fact that uncontested races provide voters with a limited pool of candidates, the method incorporates these varying choice sets by an independence of irrelevant alternatives assumption. The algorithm is formally derived in Appendix E. The assumption that makes this model tractable is that a vote in one office is independent of each other within each cluster, i.e. $\operatorname{Pr}\left(\mathbf{Y}_{i}, \mid Z_{i}=k, \pi\right)=\prod_{j=1}^{J} \prod_{\ell=1}^{L}\left(\mu_{k j \ell}\right)^{\mathbf{1}\left(Y_{i j}=\ell\right)}$. This assumption is common to virtually all clustering methods. My algorithm uses an Expectation Maximization (EM) method to identify the set of cluster assignments $Z_{i}$ that best comports with the voting patterns.

Figure 2 shows the point estimates of the cluster prevalence $\pi_{k}$ and the characteristics of each cluster $\mu_{k j \ell}$ estimated with four clusters, in the two presidential races available in the data. Each vote is recoded relative to the same voter's presidential vote, and, as in Figure 1, subsetted to voters who voted for the Democratic and Republican Presidential candidates.

Both the choice of the number of clusters $(K)$ and the substantive interpretation of each cluster is determined by the user. Although this leaves room for some ambiguity when implementing the clustering algorithm, one does not need to commit to the view that there exists a single correct number of clusters in the data. One cluster can often be divided into two slightly more homogeneous clusters. To provide some guidance, I cluster the same data with values of $K$ between 2 and 10, and compute the BIC fit statistic. I ultimately choose to present results with $K=4$ given that is where 
the fit statistics start to level off in 2016 (Appendix D). The BIC statistic uses the observed log likelihood that the EM algorithm tries to maximizes, penalized by the number of parameters it is asked to estimate. I then provide a label for each of the clusters according to the values of the estimated values of the vote choice parameters $\mu$.

In 2016, a bare majority of both Republican and Democratic voters (as inferred from their presidential vote choice) are solid partisans in their votes, because they vote solidly for the same party up and down the ticket. In 2012, only about 40 percent of the electorate is classified as solid partisans. Even in 2016, this group is not large enough a group to deliver an election-winning majority for a particular candidate, as Romney and Trump comprised about 55 percent of the state's electorate.

The second largest cluster of voters vote for the same party in congressional races but are more likely to split their ticket in state elections. This pattern is particularly noticeable among Republican voters, where for example 5 percent of Trump voters in cluster 2 split their ticket in the U.S. House but 15 to 50 percent of them split their ticket for the Democrat in their vote for the state legislature, sheriff, and county council. This cluster comprises about 35 percent of both Trump and Clinton voters, which makes them large enough a group to be pivotal even in a statewide race. The third and fourth largest clusters of voters vary in their voting patterns by year and party. Many of these groups primarily abstain after voting for President. Notably, the fourth cluster among Clinton voters appears to be solid Republicans who only broke away from their party preference in the race for President. I therefore label these anti-Trump Republicans.

Finally, the clustering differentiates ticket splitting for particular offices. Among 2012 Obama voters, for example, two out of its four clusters had substantial probabilities of splitting their ticket, but while the second largest cluster was most likely to split in the vote for state house, the third largest cluster was more likely to split in the office of sheriff.

Both Figures 1 and 2 establish the same general pattern. It does not appear that voters are blind partisans in low information races. In fact, ticket splitting is more prevalent for the majority of these state and county offices. Roll-off is also higher further down the ballot: typically around 1 percent 


\section{Figure 2: Clusters of Ticket Splitting Voting Patterns, 2012 and 2016}

\section{Among Republican Presidential Voters}

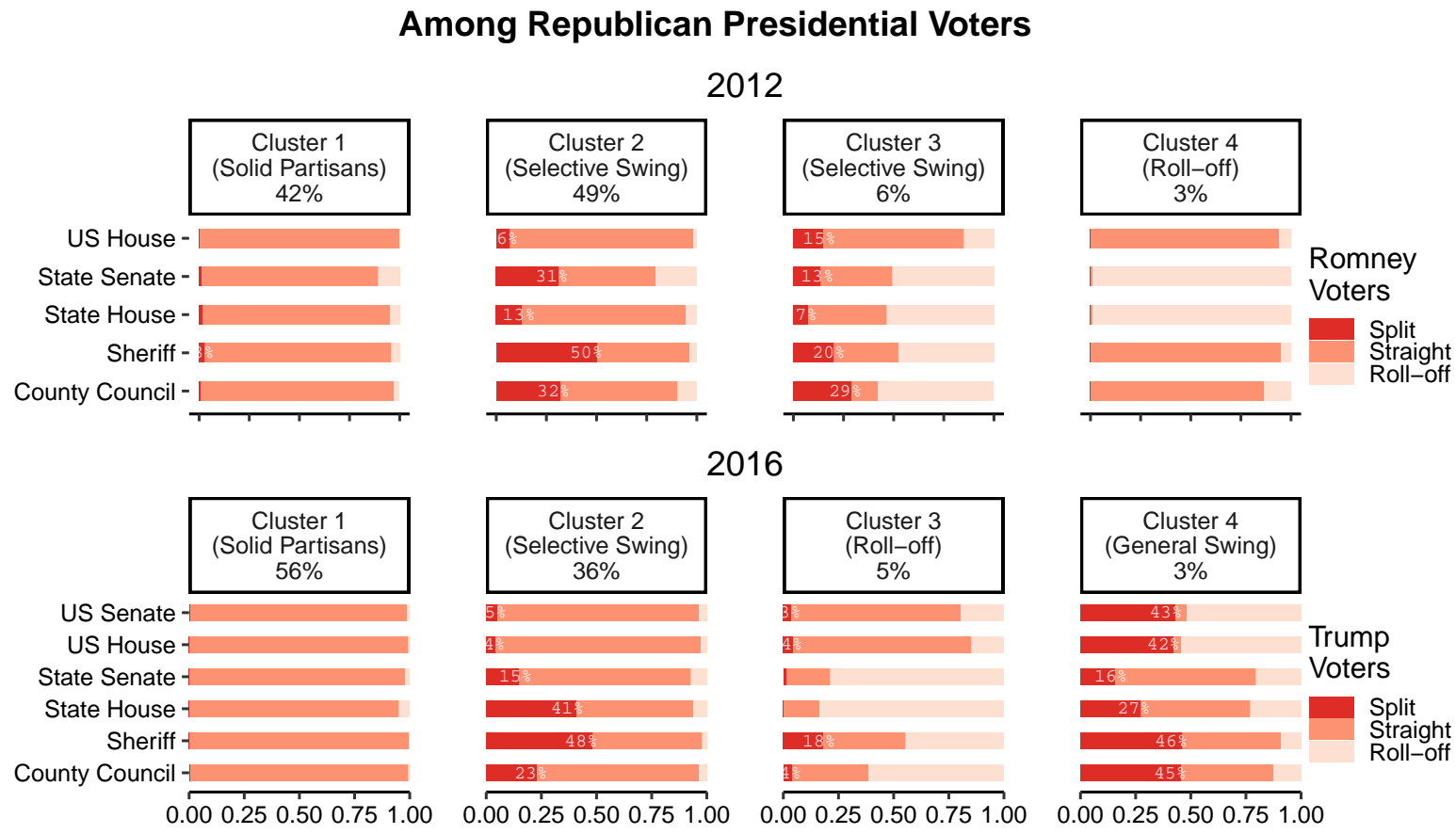

\section{Among Democratic Presidential Voters}

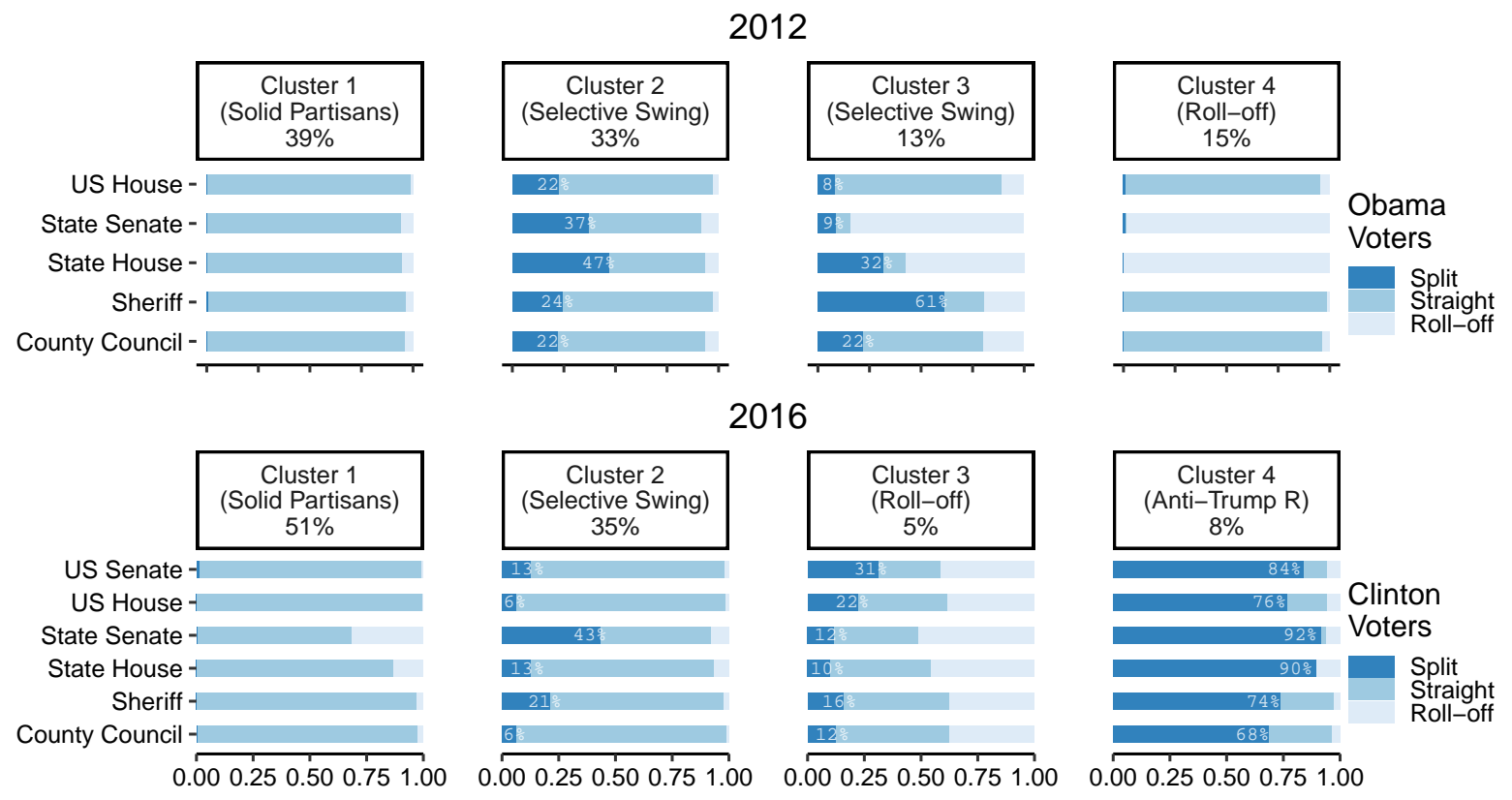

Note: Figures show estimates from the clustering method to summarize voting behavior on the long ballot. Each row of facets represents one population of voting data, and each facet within each row represents the estimated cluster. Clusters are numbered by their estimated size in the population (parameter $\pi_{k}$ ), as shown in the facet label. Within each cluster, the algorithm estimates the estimated probability that a voter in that cluster votes a certain way in a given office (parameter $\mu_{k j \ell}$ ). Vote choices are recoded so that they are relative to the voter's Presidential vote choice. Therefore, this figure analyzes South Carolina voters who voted for a major party Presidential candidate. 
in congressional elections and 2 to 4 percent in down-ballot races do not cast a vote. ${ }^{10}$ Another way to summarize this multidimensional data is to count how close voters are to casting a fully straight ticket ballot. Appendix Table D5 shows that in the modal case of a ballot with 4 contested races, 82 percent of voters are fully straight ticket voters - i.e. vote for Democrats in all four offices or vote for Republicans in all four. This rate falls with more contested races on the ballot. Therefore, despite informational theories that would predict straight ticket voting to be more prevalent in downballot races where candidate information is scarce, election day voters tend to split their ticket their national party loyalty as much as, if not more than, national congressional races.

\section{Candidate Experience and Quality Explanations}

What explains the variation in ticket splitting? Although cast vote records are anonymous, other information can be used to test the predictions from the theoretical model of spatial voting with valence. Information about a candidate's incumbency, newspaper exposure, and quality can be merged in for cross-candidate variation. Second, a voter's partisan vote for top of the ticket contests can be used to study whether the effect of candidate quality varies by partisan consistency.

\section{Difference between Incumbents, Challengers, and Open-Seats}

Voters who care about candidate experience would, in my theoretical framework, think twice about casting a straight ticket vote when they reach a down-ballot office and realize that a straight ticket vote implies choosing an inexperienced challenger. I first provide simple differences between incumbents and challengers to test this claim. I subset the data to six offices with a sufficient number of contested contests in enough districts, and further subset to contests that featured an incumbent running for re-election against a major party challenger. After these restrictions, we are left with

10 This rate is smaller compared to those reported in other studies of roll-off, which show roll-off to be about 5 10 percent. However, most of these other studies examine non-partisan elections or ballot measures. Additionally, my analysis take voters who have already voted for a major party at the top of the ticket as its denominator. South Carolina's use of DRE touchscreen ballots and the option of the party lever likely decreases roll-off in partisan contests. I find larger proportions of roll-off in Maryland and Arizona, both of which use paper ballots (Figures D4 and D5). 
Table 2: Straight Ticket Rates by Incumbency

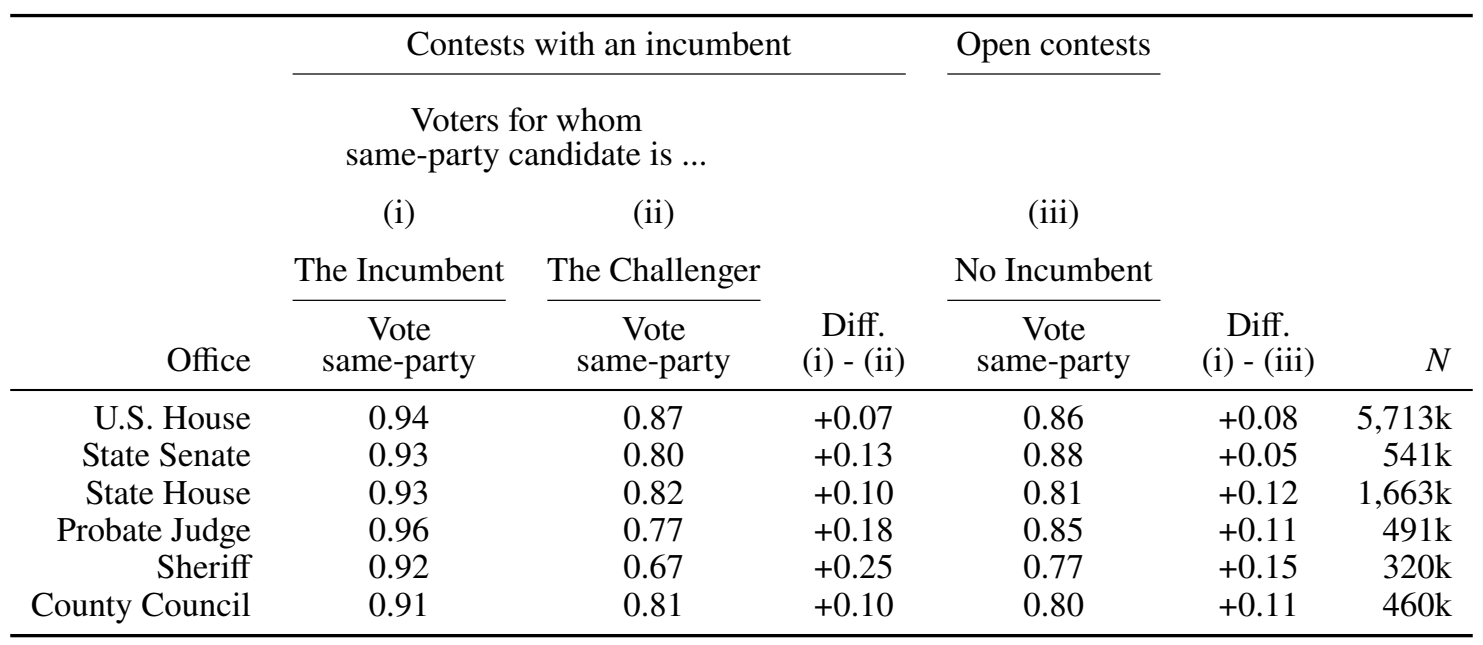

Note: Proportions show straight party voting rates between six offices and the top of the ticket (President or Governor) by candidate incumbency. The difference between (i) and (ii) indicate the difference in straight ticket voting associated with incumbency (as opposed to being a challenger). The difference between (i) and (iii) indicate the difference between an incumbent and an open race with no incumbent. Number of voters for the entire row listed in 1000s.

529,464 split ticket votes (as defined in Figure 1) cast by 467,412 voters. In each of these split ticket choices where the voter could choose between the incumbent or the challenger, a clear majority of 68 percent voted for the incumbent.

Open-seat contests serve as a useful comparison because incumbency is not at play. In Table 2, I show the proportion of the straight ticket voting rates separated by the presence of an incumbent and the party affiliation of the incumbent. If voters value the qualities associated with incumbency, we would expect to see the most same-party votes when the incumbent is of the same party as the voter's top of the ticket choice (case i). We would expect fewer same-party votes when entails voting against the incumbent (case ii). Finally, the rate of straight ticket voting when there is no incumbent (case iii) should be lower than case (i) but higher than case (ii).

Consistent with those expectations, straight ticket voting is highest when doing so coincides with voting for the incumbent across the six offices in Table 2. Among contested U.S. House races, 94 percent of voters whose party choice at the top of the ticket happened to align with the party affiliation of their U.S. House incumbent voted for that incumbent (column i). But when they did not align (column ii), only 87 percent of these voters voted straight ticket, indicating a split ticket to 
vote for the incumbent. The rate in open-seats where no incumbent exists (column iii) tends to fall in the middle of the two values for all offices. If voters did not value the qualities associated with incumbency, all three proportions for each office would have been the same. Instead, we see sizable differences.

\section{Contributions of valence controlling for partisanship}

An individual-level regression allows for a more controlled comparison, modeling vote choice after matching individuals of similar revealed preferences in national offices. For each voter $i$ making a choice for office $j$ on their ballot, ticket splitting can be modeled from a linear probability model of the form

$$
W_{i j}=\alpha+g\left(D_{i}\right)+\gamma_{0} V_{c[i j]}+\gamma_{1} D_{i} V_{c[i j]}+\varepsilon_{i, c[i j]}
$$

Here the binary outcome $W_{i j}$ is 1 if individual $i$ votes for the same party in office $j$ as they did for at the top of the ticket. The control $D_{i}$ measures the voter's general party preference towards the Democrat by the proportion of times a voter chose the Democrat in the top of the ticket contests: President, Governor, U.S. Senate, and the party lever. The model interacts this with the valence advantage in that contest, denoted by $V_{c[i j]}$, to allow for the contribution of candidate attributes to vary by the partisan lean of the voter. I code valence $V$ so that positive values indicate the valence advantage of the Republican candidate, indexed by the district of office $j$ in which voter $i$ resides $(c[i j])$. Accordingly, I cluster standard errors by letting errors $\varepsilon_{i, c[i j]}$ be potentially correlated across individuals within a district. The function $g$ allows for partisan preference $D_{i}$ to vary flexibly; here I use a second-order polynomial.

Several variables serve as measures of the valence advantage. The first is an indicator for whether or not the Republican candidate in a (closed) contest is an incumbent. To measure other aspects of valence that can be defined in open-seat races, I also use the Republican advantage in newspaper coverage and in campaign contributions. I summarize the candidate data by taking the ratio of the 


\section{Figure 3: Contribution of Valence Attributes to Ticket Splitting}
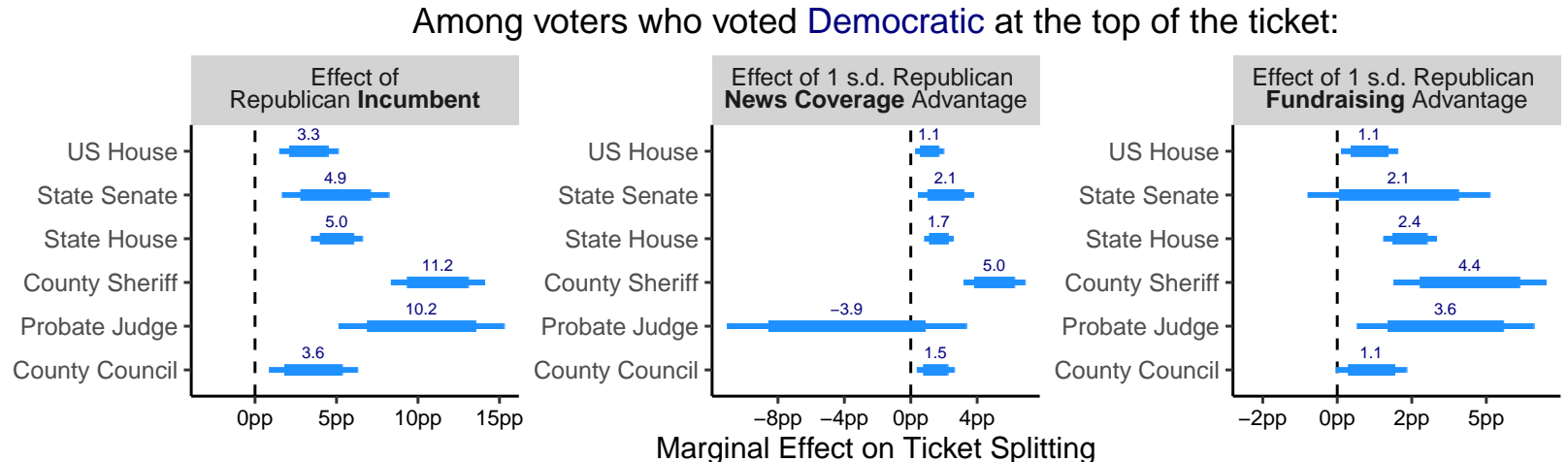

Among voters who voted Republican at the top of the ticket:
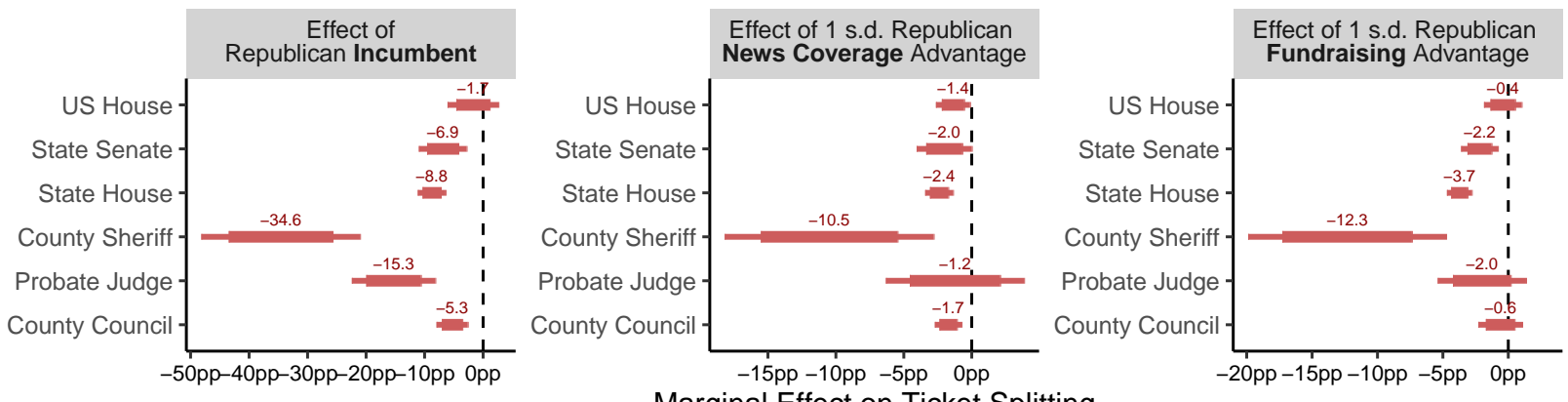

Note: Each coefficient shows marginal effects in percentage points from a separate regression, each following equation (1). Left panels: coefficient on Republican incumbency, center panels: coefficient on Republican news advantage, right panels: coefficient on Republican fundraising advantage. Values in the center and right panels are rescaled so that it represents a one-standard deviation increase. The top panel estimates the marginal effect of a Republican valence advantage among top of the ticket Democratic voters, i.e. those for whom $D_{i}=1$. The bottom panel estimates the same marginal effects among top of the ticket Republican voters, i.e. those for whom $D_{i}=0$. Numbers are point estimates; Intervals indicate 80 percent and 95 percent confidence intervals using standard errors clustered by contest.

Republican candidate's metric over the Democrat's so that positive values indicate a Republican advantage, and then take the log of the ratio to model diminishing returns of newspaper coverage and campaign contributions (See Appendix B.6). Both measures are likely endogenous to each other, so I enter each measure of valence one by one into separate regressions.

Figure 3 presents the marginal effect estimate for each of the three measures of valence. This amounts to estimating the effect of a one-unit increase in $V_{c[j]}$ in equation (1) holding the variable each individual's voteshare at the top of the ticket $\left(D_{i}\right)$ constant. Because the effect of a Republican valence advantage likely moves moderate and extreme voters to varying extents, I estimate marginal effects at each endpoint of the distribution of proportion $D_{i}$, where most of the data lies. If voters are 
complete straight-ticket voters, their straight ticket voting would be completely explained by their top of the ticket choices and all other coefficients would be indistinguishable from zero. Conversely, if voters could perceive and value candidate valence, the valence advantage of the Republican should attract ticket splitting from Democrats.

Figure 3 shows that incumbents draw more split ticket votes. Each point can be interpreted as the conditional difference in the probability of deviating from the top of the ticket when the Republican is the incumbent, compared to when the Democrat is the incumbent. First, consider the top-left figure. In all offices, but especially those that are the Sheriff or State House, even voters who vote exclusively for Democrats at the top of the ticket (i.e., $D_{i}=1$ ) are more likely to split their ticket to vote for the incumbent. The bottom-left figure estimates the same difference among voters who vote exclusively for Republicans at the top of the ticket $\left(D_{i}=0\right)$. Having a Republican incumbent in the race is associated with a 5-10 percentage point smaller probability of deviating from their Republican vote at the top of the ticket. In other words, co-partisan incumbents solidify partisans' down-ballot vote but out-partisan incumbents draw ticket splitting. Figure D7 visualizes these differences for voters who lean towards one of the parties but not exclusively. The difference in ticket splitting is even larger among these weak partisans, with estimates ranging from 10 percentage points in county council to 30 percentage points in the choice for sheriff.

The coefficients for newspaper coverage and fundraising advantage in the center and right figures of Figure 3 show similar patterns of ticket splitting. For all but one office with a noisy estimate (probate judge), when the Republican candidate has more newspaper coverage or more contributions than the Democratic candidate, they tend to attract more votes from Democratic leaning voters (compared to contests when the candidate does not have such an advantage), and reduce defections among Republican leaning voters. A one-unit increase on a party's log ratio advantage measure is associated with about a 2-3 percentage point increase in ticket splitting in the opposing party. Substantively, this implies that a one standard deviation increase in the Republican money or news advantage is associated with about a 1 percentage point increase in ticket splitting in the U.S. House, 2-3 percentage points in the state legislature, 5-10 percentage points in the sheriff, and 1-1.5 per- 
centage point for county council. ${ }^{11}$

These estimated effects of incumbency in state and local races persist for several offices also after controlling for newspaper coverage and the campaign fundraising in the same regression (Appendix D). These findings suggest that incumbency is not merely a proxy for name familiarity and news coverage. Although the multivariate regressions cannot pinpoint the specific mechanism at play, it suggests that voters both can perceive and care about the range of factors that originates from experience on the job and other reputational advantages.

\section{Correlates with Measures of Candidate Quality}

To address the concern that measures such as incumbency, newspaper appearances, and fundraising may merely represent candidate visibility and not necessarily candidate quality, I analyze a subset of contests for which a endorsement-based measure of candidate quality exists. Consistent with the previous analyses, ticket splitting positively correlates with candidate quality based on this measure.

I use the measure of candidate quality estimated from newspaper endorsements by DeLuca (2022). The main idea behind these estimates is that newspapers prefer to endorse the candidate that is most capable and experienced for the job, all else equal. DeLuca (2022) infers the underlying quality of competing candidates by newspapers' endorsements from 1950-2020, netting out the newspaper's own ideological slant. The strength of this measure is that it is based on a more holistic assessment by journalists, who often conduct in-person interviews of the candidates. Unlike other measures of candidate quality (Buttice and Stone 2012), this measure also covers offices beyond Congress including state legislators, state Attorneys General, and county commissioners.

I identify 15 contests where both my cast vote record measure and DeLuca's newspaper endorsement measure of candidate quality are available. A precondition of this endorsement measure is that at least two different newspapers to make endorsements in the same contest to infer quality. Otherwise, a candidate's quality cannot be disentangled from the newspaper favoring the candidate

11 Because log ratios are difficult to substantively interpret, in the Figure I rescale each coefficient so that it represents the change in probability from a one standard deviation increase. The standard deviation is computed at for each office and ranges from 2 to 4 (Table B2). 
Figure 4: Candidate Quality Correlates with Ticket Splitting

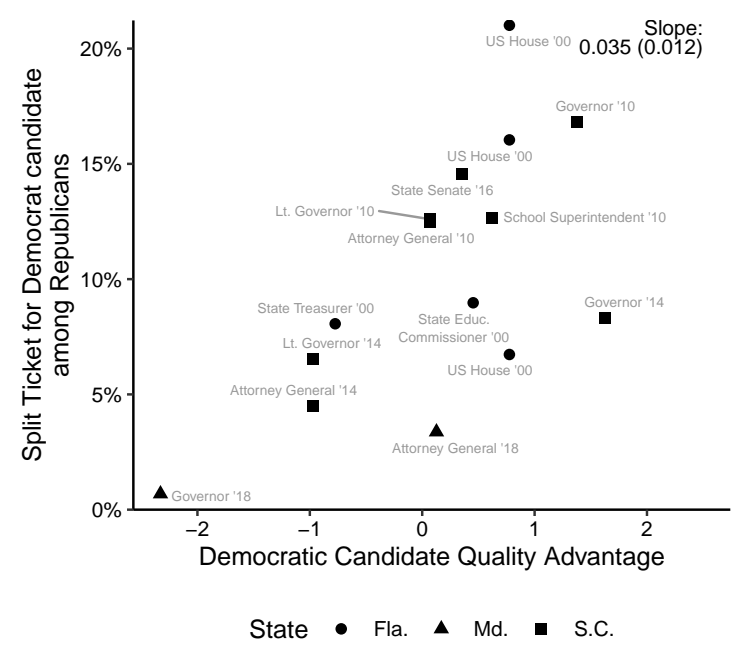

Note: Democratic Candidate Quality Advantage comes directly from DeLuca (2022). Estimates come from a spatial model of newspapers making endorsements based on quality and their own ideological slant. Points show all contests in my collection of cast vote records that are given quality estimates in DeLuca's data. The vertical axis is the percent of Republican top-of-ticket voters who split their ticket for the Democratic candidate in the contest. Contest names and years are labelled in gray. The OLS coefficient from a bivariate regression is shown in the top-right corner, with the standard error in parenthesis.

because of aligned partisan slants. The closing of state newspapers in recent years have therefore limited the number of contests for which a quality measurement exists. I expand my search to the three cast vote record datasets outside South Carolina, resulting in the 15 candidates across national, state, and local offices in three states.

Figure 4 shows that the relationship between a candidate's quality advantage against his opponent and the degree of ticket splitting they benefit from out-partisans is positive. DeLuca's quality measure is defined as a relative advantage of the Democratic candidate relative to her Republican opponent in each contest. The measure is standardized to unit variance and most of the estimates range from -2 to 2 in the entire 1950-2020 period. Therefore, on the vertical axis I use the percent of top of the ticket Republican voters who vote for the Democratic candidate. The slope is 3.5 percentage points with a standard error of 1.2 , indicating a one standard deviation increase in the quality advantage is associated with a 3.5 point higher degree of ticket splitting by the higher quality candidate.

Part of the positive correlation we observe may be a causal effect of winning an endorsement. 
Much like the newspaper coverage measure in Figure 3, voters may be splitting their ticket for the endorsed candidate simply because they saw the candidate in the news more, instead of knowing that the candidate is of higher quality. However, using the subset of the same data, DeLuca (2023) estimates that the causal effect of endorsements per se are only about one fourth of the size of the association he finds between quality and electoral success.

In summary, the deviations from straight ticket voting in the previous section systematically benefit the candidate with the higher quality advantage. Across four sets of valence measures, I find that ticket splitting systematically benefits candidates who have relevant experience as incumbents, are better known, raise more money from voters, and are evaluated as higher quality through endorsements. This occurs even though these ballots do not display the candidate's incumbency status or any other information about the candidate beyond their party label, suggesting that there are informational signals that sufficiently distinguish the higher valence candidate in these offices.

\section{Generalizability}

One limitation of these findings is that they examine contested races in a single state. In Appendix Figures D4 - D6, I analyze the cast vote records in three other states: Maryland, Arizona, and Florida, and find similar patterns of higher ticket splitting in state and local offices. In the city of Baltimore in 2020, 94 percent of Joe Biden voters voted for the Democratic candidate in the U.S. House election, but only 78 percent of the same voters voted for the Democratic candidate in the open-seat election for mayor (Figure D4). In Maricopa County, 93 percent of Donald Trump voters voted for Martha McSally (R) in the U.S. Senate race but only 82 percent of the same voters voted for the Republican sheriff candidate, who went on to lose to the one-term Democratic incumbent (Figure D5).

Several other considerations suggest that in most contemporary U.S. contexts, ticket splitting is similar or higher in state and local elections. First, consider how this pattern varies by the degree of two-party contestation. South Carolina state legislative elections are one of the less contested in 
the country. ${ }^{12}$ My theoretical framework predicts that split ticket rates would be higher if parties contested more districts. The premise of this prediction is that uncontested districts tend to be those where the disadvantaged party's chance of victory is already slim (Rogers 2015). Therefore, voters who value valence would be even more likely to cross party lines if a disadvantaged party were to enter a lopsided race.

My theoretical framework further suggests that ticket splitting would be less prevalent in downballot races where candidate-specific information is sparse, two-party competition is high, and the incumbency advantage is weak. One might worry that South Carolina is an outlier in this regard, with many lopsided districts. But it is in fact empirically rare for any voter to reside in an enclave where all congressional, statewide, and state legislative elections are uncompetitive (Fraga and Hersh 2018). South Carolina is no exception. The long ballot and the high degree of district overlap in the U.S. electoral system mean that most voters' long ballots feature competitive contests as well as uncompetitive ones.

Another concern when predicting patterns in other states is South Carolina's history as a Southern state, where Democrats such as Strom Thurmond switched to the Republican party in a massive realignment in the 1960s and 1970s (also documented in Table C3). Perhaps some of the patterns here are driven by older voters who, like in the election of Eisenhower, voted for Republican national candidates but Democratic candidates in state and local elections. However, realignment is a common feature of a two party system and many non-Southern states experienced realignments. The logic of the valence advantage also does not rely on such massive realignments. The findings in Arizona and Maryland are consistent with this idea.

I now turn to the more speculative question of whether the dynamics of split ticket voting documented here will eventually disappear in an era of increasing nationalization. Across eight year period of 2010-2018 in South Carolina, I do find an uptick in the rates of straight ticket voting overtime (Appendix Section D.4) consistent with analysis of aggregate data with near-national coverage (Rogers 2023). How these rates would change beyond the sample depends on future party alignment

12 See Ballotpedia, https://perma.cc/HR3U-TV7L. 
in national politics. My results do suggest that the incumbency advantage is still a significant force in state and local elections, and may delay the tides of nationalization that has swept congressional and gubernatorial elections.

\section{Conclusion}

The picture of the electorate that emerges from these analyses is one that votes largely along party lines, but still varies across offices and candidate quality. Some questions regarding interpretation remain: Should the levels of party line voting found here be interpreted as still too high? A traditional view of local politics has been that it is void of partisanship (but see Tausanovitch and Warshaw 2014; Bucchianeri 2020). In a strong version of this view, the party loyalty found here may be considered still too high. Whether high party loyalty should be considered blind partisanship or a failure of accountability also depends on the degree to which parties in these local offices implement different policies.

In either case, the findings presented here would not have been obvious without empirical investigation. Extending the nationalization literature into state and local politics, one might have predicted that the rate of ticket splitting would be equally low for all offices. And extending theories of partisanship as an informational shortcut, one might have predicted that, if anything, ticket splitting to be less likely in down ballot races than in national ones.

The empirical findings do not lend support for these predictions. Contests for state and local offices routinely feature more ticket splitting. Within-office variation is explained by a theory of candidate valence differentials: For example, incumbents systematically netted more votes from ticket splitting than challengers, even after controlling for a voter's own party allegiance at the top of the ticket (Table 2, Figure 3). Ticket splitting also correlates with a measure of candidate valence that more explicitly measures candidate quality rather than simply news exposure (Figure 4). My theoretical framework clarifies that even if nationalization has so thoroughly polarized candidates such that state and local candidates follow the national partisan platforms, ticket splitting can still occur through a difference in candidate quality. 
By constructing the first database of cast vote records spanning entire states across multiple elections, this study has overcome some of the most common challenges that researchers face in studying vote choice for state and local office. In addition to ticket splitting, cast vote records allow researchers to study vote choice in party primaries, ballot measures, and elections for non-partisan offices (i.e., those without party labels and party primaries) such as school board elections. Existing studies of these three types of elections are limited by the same sort of measurement problems that can be alleviated with wider use of cast vote records. Cast vote records do have inherent limitations - they reveal how people vote, but reveal less about the demographic characteristics of those voters (Table 1). Future research that combines cast vote records with precinct-level data could help distinguish more carefully the process through which voters form their preferences for state and local offices.

The long ballot and a two-party system are defining features of U.S. electoral institutions (Key 1963; Chhibber and Kollman 2004). Voter's choices on these ballots across the range of national, state, and local offices are the locus of the major trends in American politics: realignment, polarization, the rise and fall of the incumbency advantage, and nationalization. On election day, voters must make a series of choices with limited information about each candidate. But after an accumulation of campaign outreach, media coverage, and information acquired through everyday observation, a considerable number of voters deviate from a complete straight ticket vote. 


\section{REFERENCES}

Abramowitz, Alan I., and Steven Webster. 2016. "The Rise of Negative Partisanship and the Nationalization of U.S. Elections in the 21st Century." Electoral Studies 41:12-22.

Alvarez, R. Michael, Thad E. Hall, and Ines Levin. 2018. "Low-Information Voting: Evidence From Instant-Runoff Elections." American Politics Research 46 (6): 1012-1038.

Amlani, Sharif, and Carlos Algara. 2021. "Partisanship \& nationalization in American elections: Evidence from presidential, senatorial, \& gubernatorial elections in the U.S. counties, 18722020.” Electoral Studies 73:102387.

Arceneaux, Kevin. 2006. "The Federal Face of Voting: Are Elected Officials Held Accountable for the Functions Relevant to their Office?" Political Psychology 27 (5): 731-754.

Bafumi, Joseph, Michael C. Herron, Seth J. Hill, and Jeffrey B. Lewis. 2012. "Alvin Greene? Who? How Did He Win the United States Senate Nomination in South Carolina?" Election Law Journal 11 (4): 358-379.

Beck, Paul Allen, Lawrence Baum, Aage R. Clausen, and Charles E. Smith. 1992. "Patterns and Sources of Ticket Splitting in Subpresidential Voting." American Political Science Review 86 (4): 916-928.

de Benedictis-Kessner, Justin. 2017. "Off-Cycle and Out of Office: Election Timing and the Incumbency Advantage." The Journal of Politics 80 (1): 119-132.

de Benedictis-Kessner, Justin, and Christopher Warshaw. 2020. "Politics in Forgotten Governments: The Partisan Composition of County Legislatures and County Fiscal Policies." The Journal of Politics 82 (2): 460-474.

Besley, Timothy, and Stephen Coate. 2008. “Issue Unbundling via Citizens' Initiatives.” Quarterly Journal of Political Science 3 (4): 379-397.

Broockman, David E. 2016. “Approaches to Studying Policy Representation.” Legislative Studies Quarterly 41 (1): 181-215.

Bucchianeri, Peter. 2020. "Party Competition and Coalitional Stability: Evidence from American Local Government." American Political Science Review 114 (4): 1055-1070.

Buell, Duncan A., Eleanor Hare, Frank Heindel, Chip Moore, and Barbara Zia. 2011. "Auditing a DRE-Based Election in South Carolina." In Proceedings of the 2011 conference on Electronic voting technology / workshop on trustworthy elections. 
Burden, Barry C., and Philip Edward Jones. 2009. "Strategic Voting in the USA.” Duverger's Law of Plurality Voting: The Logic of Party Competition in Canada, India, the United Kingdom and the United States, 47-64.

Burden, Barry C., and David C. Kimball. 2002. Why Americans Split Their Tickets: Campaigns, Competition, and Divided Government. University of Michigan Press.

Buttice, Matthew K., and Walter J. Stone. 2012. "Candidates matter: Policy and Quality Differences in Congressional Elections.” The Journal of Politics 74 (3): 870-887.

Chhibber, Pradeep, and Ken Kollman. 2004. The Formation of National Party Systems Federalism and Party Competition in Canada, Great Britain, India, and the United States. Princeton University Press.

Darr, Joshua P., Matthew P. Hitt, and Johanna L. Dunaway. 2018. "Newspaper Closures Polarize Voting Behavior." Journal of Communication 68:1007-1028.

Davis, Nicholas T., and Lilliana Mason. 2016. "Sorting and the Split-Ticket: Evidence from Presidential and Subpresidential Elections." Political Behavior 38 (2): 337-354.

DeLuca, Kevin. 2022. "Newspaper Endorsements, Candidate Quality, and Election Outcomes in the United States, 1950-2020." APSA Preprints.

—. 2023. "The Influence of Biased Local Newspaper Endorsements.”

Djourelova, Milena, Ruben Durante, and Gregory Martin. 2021. "The impact of online competition on local newspapers: Evidence from the introduction of Craigslist."

Eggers, Andrew C. 2017. "Quality-Based Explanations of Incumbency Effects.” The Journal of Politics 79 (4): 1315-1328.

Farris, Emily M., and Mirya R. Holman. 2017. “All Politics Is Local? County Sheriffs and Localized Policies of Immigration Enforcement.” Political Research Quarterly 70 (1): 142-154.

Fraga, Bernard L., and Eitan D. Hersh. 2018. "Are Americans Stuck in Uncompetitive Enclaves? An Appraisal of U.S. Electoral Competition." Quarterly Journal of Political Science 13 (3): $617-627$.

Gerber, Elisabeth R., and Jeffrey B. Lewis. 2004. "Beyond the Median: Voter Preferences, District Heterogeneity, and Political Representation.” Journal of Political Economy 112 (6): 13641383.

Groseclose, Tim. 2007. "A Model of Candidate Location When One Candidate Has a Valence Advantage." American Journal of Political Science 45 (4): 862-886. 
Hansen, Jeremy A. 2015. "Ballot-Level Observations about Vermont's 2014 General Election." New England Journal of Political Science 8 (2): 186-217.

Herron, Michael C., and Jeffrey B. Lewis. 2007. "Did Ralph Nader Spoil a Gore presidency? A Ballot-level Study of Green and Reform Party Voters in the 2000 Presidential Election." Quarterly Journal of Political Science 2 (3): 205-226.

Hopkins, Daniel J. 2018. The Increasingly United States: How and Why American Political Behavior Nationalized. University of Chicago Press.

Jacobson, Gary C. 2015. "It's Nothing Personal: The Decline of the Incumbency Advantage in US House Elections." The Journal of Politics 77 (3): 861-873.

- 2021. "The presidential and congressional elections of 2020: A national referendum on the Trump presidency." Political Science Quarterly 136 (1): 11-45.

Jensen, Amalie, William Marble, Kenneth Scheve, and Matthew J. Slaughter. 2021. "City Limits to Partisan Polarization in the American Public." Political Science Research and Methods 9 (2): 223-241.

Key, V. O. 1963. American State Politics: An Introduction. Knopf.

King, Gary. 1997. A Solution to the Ecological Inference Problem. Princeton University Press.

Kuriwaki, Shiro. 2020. "The Administration of Cast Vote Records in U.S. States." OSF Preprints, $1-13$.

Linzer, Drew A., and Jeffrey B. Lewis. 2011. "poLCA: An R Package for Polytomous Variable Latent Class Analysis.” Journal of Statistical Software 42 (10): 1-18.

Morse, Michael. 2021. "The Future of Felon Disenfranchisement Reform: Evidence from the Campaign to Restore Voting Rights in Florida.” California Law Review 109:1143-1197.

Moskowitz, Daniel J. 2020. "Local News, Information, and the Nationalization of U.S. Elections." American Political Science Review 115 (1): 114-129.

Oliver, J. Eric, Shang E. Ha, and Zachary Callen. 2012. Local Elections and the Politics of SmallScale Democracy. Princeton University Press.

Park, Won-ho, Michael J. Hanmer, and Daniel R. Biggers. 2014. "Ecological Inference under Unfavorable Conditions: Straight and Split-ticket Voting in Diverse Settings and Small Samples." Electoral Studies 36:192-203. 
Peterson, Erik. 2017. “The Role of the Information Environment in Partisan Voting." The Journal of Politics 79 (4): 1191-1204.

Prat, Andrea, Riccardo Puglisi, and James M. Snyder. 2010. "Is Private Campaign Finance a Good Thing? Estimates of the Potential Informational Benefits." Quarterly Journal of Political Science 5 (3): 291-318.

Rogers, Steven. 2015. "Strategic Challenger Entry in a Federal System: The Role of Economic and Political Conditions in State Legislative Competition." Legislative Studies Quarterly 40 (4): 539-570.

_. 2017. "Electoral Accountability for State Legislative Roll Calls and Ideological Representation." American Political Science Review 111 (3): 555-571.

—. 2023. "The Vanishing Incumbency Advantage in State House Elections." The Forum.

Shor, Boris, and Nolan McCarty. 2011. "The Ideological Mapping of American Legislatures." American Political Science Review 105 (3): 530-551.

—. 2022. “Two Decades of Polarization in American State Legislatures.” Journal of Political Institutions and Political Economy 3 (3-4): 343-370.

Sievert, Joel, and Seth C. McKee. 2018. "Nationalization in U.S. Senate and Gubernatorial Elections." American Politics Research, 1-26.

Tausanovitch, Chris, and Christopher Warshaw. 2014. "Representation in Municipal Government." American Political Science Review 108 (03): 605-641.

Thompson, Daniel M. 2019. "How Partisan Is Local Law Enforcement? Evidence from Sheriff Cooperation with Immigration Authorities.” American Political Science Review, 222-236.

Trounstine, Jessica. 2011. "Evidence of a Local Incumbency Advantage.” Legislative Studies Quarterly 36 (2): 255-280.

- 2018. "Political Schizophrenics? Factors Affecting Aggregate Partisan Choice at the Local Versus National Level." American Politics Research 46 (1): 26-46.

Wakefield, Jon. 2004. "Ecological Inference for 2 x 2 Tables." Journal of the Royal Statistical Society Series A, 385-445.

Warshaw, Christopher. 2019. "Local Elections and Representation in the United States." Annual Review of Political Science 22:461-479. 
Zoorob, Michael. 2022. "There's (rarely) a new sheriff in town: The incumbency advantage for local law enforcement." Electoral Studies 80:102550. 


\section{Appendix for: "Ticket Splitting in a Nationalized Era"}

April 3, 2023

A A Model of Spatial Voting with a Valence Advanage 2

B Data Construction 6

B.1 Data Construction . . . . . . . . . . . . . 6

B.2 The iVotronic Voting Machine . . . . . . . . . . . 7

B.3 Cast Vote Records from Other States . . . . . . . . . . . . 7

B.4 Data on Newspaper Mentions . . . . . . . . . . . . . . 10

B.5 Data on Campaign Contributions . . . . . . . . . . . . 13

B.6 Summary Statistics for the Valence Advantage . . . . . . . . . 14

C Elections in South Carolina 16

C.1 Historical Trends in South Carolina Elections . . . . . . . . 16

C.2 Elections and Offices Covered . . . . . . . . . . 17

D Additional Findings $\quad 18$

D.1 Split Ticket Voting by Election, Party, and Office. . . . . . . . 18

D.2 Distribution of Ticket Splitting Rates . . . . . . . . . . . . . 25

D.3 The Valence Advantage: Additional Results . . . . . . . . . 25

D.4 Overtime Change in Party Loyalty . . . . . . . . . . . . . . 29

E Clustering Algorithm 30

E.1 Setup ......................... 30

E.2 EM Algorithm, Fully Contested Case . . . . . . . . . . 31

E.3 Modeling Uncontested Races . . . . . . . . . . . . . . . 33

E.4 Selection of the Number of Clusters . . . . . . . . . . 35 


\section{Appendix A: A Model of Spatial Voting with a Valence Advanage}

This section clarifies the theoretical framework described in the main text as a spatial model. This constitutes an application of valence models (Ansolabehere and Snyder 2000; Groseclose 2007) to the case of ticket splitting.

Setup This is a non-strategic and non-dynamic probabilistic voting model with only one player: the voter $i$. The voter makes a binary choice in each of $j \in 1, \ldots, J$ offices. Voters have ideal point $x_{i}^{*} \in \mathbb{R}$.

Candidates are members of a party $a \in\{\mathrm{L}, \mathrm{R}\}$ and run for one office $j$. We let $\mathrm{L}$ stand for Democrat and $\mathrm{R}$ for Republican. Candidates have two fixed attributes: their policy position $x_{j}^{a} \in \mathbb{R}$ and valence $v_{j}^{a} \in \mathbb{R}$. Both their policy and valence are fixed, for example by constraints in the primary election or party organizations.

Each outcome $y_{i j} \in\{\mathrm{L}, \mathrm{R}\}$ refers to a party choice by voter $i$ in office $j$. Voters prefer candidates with closer policy positions, but they may also prefer more valence over less. Therefore in contest $j$ a voter considers a quadratic utility for each party $a$ with random measurement error:

$$
\begin{aligned}
& U_{i}\left(x_{j}^{\mathrm{L}}, v_{j}^{\mathrm{L}}\right)=-\left(x_{i}^{*}-x_{j}^{\mathrm{L}}\right)^{2}+\theta v_{j}^{\mathrm{L}}+\ell_{i j} \\
& U_{i}\left(x_{j}^{\mathrm{R}}, v_{j}^{\mathrm{R}}\right)=-\left(x_{i}^{*}-x_{j}^{\mathrm{R}}\right)^{2}+\theta v_{j}^{\mathrm{R}}+r_{i j}
\end{aligned}
$$

The parameter of interest is $\theta \in \mathbb{R}$, which indicates the weight voters assign to valence relative to party. If $\theta=0$, then voters only ignore valence and vote party. If $\theta>0$, some voters may defect from their party allegiance to vote for a high quality candidate. We now let it vary by $i$.

Decision Rule Let the errors be such that $\left(\ell_{i j}-r_{i j}\right) \sim \operatorname{Normal}(0,1)$. In other words, both of the errors have a Normal distribution with the same mean, with the variance of the difference of the two distributions being 1 . Then the probability that voter $i$ votes for the Democrat (candidate $\mathrm{L}$ ) in office $j$ is given by

$$
\begin{aligned}
\operatorname{Pr}\left(y_{i j}=\mathrm{L}\right) & =\operatorname{Pr}\left(U_{i}\left(x_{j}^{\mathrm{L}}, v_{j}^{\mathrm{L}}\right)>U_{i}\left(x_{j}^{\mathrm{R}}, v_{j}^{\mathrm{R}}\right)\right) \\
& =\operatorname{Pr}\left(r_{i j}-\ell_{i j}<\left(-\left(x_{i}^{*}-x_{j}^{\mathrm{R}}\right)^{2}+\theta_{i} v_{j}^{\mathrm{R}}\right)-\left(-\left(x_{i}^{*}-x_{j}^{\mathrm{L}}\right)^{2}+\theta_{i} v_{j}^{\mathrm{L}}\right)\right) \\
& =\Phi\left(2\left(x_{j}^{\mathrm{L}}-x_{j}^{\mathrm{R}}\right)^{\prime}\left(x_{i}^{*}-\frac{\left(x_{j}^{\mathrm{L}}+x_{j}^{\mathrm{R}}\right)}{2}\right)+\theta_{i} \cdot\left(v_{j}^{\mathrm{L}}-v_{j}^{\mathrm{R}}\right)\right)
\end{aligned}
$$

where $\Phi(\cdot)$ is the cumulative density function of a standard Normal distribution. In other words, a 
voter's choice for a particular election depends on the spatial differential $\Delta x_{j} \equiv x_{j}^{\mathrm{L}}-x_{j}^{\mathrm{R}}$ combined with the cutpoint $\left(\kappa_{j} \equiv \frac{\left(x_{j}^{\mathrm{L}}+x_{j}^{\mathrm{R}}\right)}{2}\right)$. We call this a valence advantage $\Delta v_{j} \equiv v_{j}^{\mathrm{L}}-v_{j}^{\mathrm{R}}$. In the empirical analysis, we denote $V_{j}$ as a valence advantage coded so that Republican valence advantages are counted as positive.

$$
\operatorname{Pr}\left(y_{i j}=\mathrm{L}\right)=\Phi\left(2\left(\Delta x_{j}\right)^{\prime}\left(x_{i}^{*}-\kappa_{j}\right)+\theta_{i} \cdot \Delta v_{j}\right)
$$

Valence advantages can therefore lead voters to split their ticket, which in this model corresponds to choosing a candidate that would not have been chosen based on the spatial cutpoint $\kappa_{j}$.

The Impact of Valence The size of the valence impact is determined by its size relative to the spatial differential. To see this, consider the one-dimensional case and solve for $\operatorname{Pr}\left(y_{i j}=\mathrm{L}\right)>0.5$. Rearranging terms and assuming $x_{j}^{\mathrm{L}}<x_{j}^{\mathrm{R}}$ without loss of generality,

$$
\begin{aligned}
& \text { Vote for } \mathrm{L} \text { if: } 2\left(x_{j}^{\mathrm{L}}-x_{j}^{\mathrm{R}}\right)\left(x_{i}^{*}-\kappa_{j}\right)+\theta_{i}\left(v_{j}^{\mathrm{L}}-v_{j}^{\mathrm{R}}\right)>0 \\
& \Rightarrow x_{i}^{*}<\kappa_{j}+\frac{\theta_{i}\left(v_{j}^{\mathrm{L}}-v_{j}^{\mathrm{R}}\right)}{2\left(x_{j}^{\mathrm{R}}-x_{j}^{\mathrm{L}}\right)} .
\end{aligned}
$$

Here we see that valence moves the original cutpoint $\left(\kappa_{j}\right)$ in L's favor from by an additive factor. This factor is increasing in $\theta_{i}$ and $\left(v_{j}^{\mathrm{L}}-v_{j}^{\mathrm{R}}\right)$, and decreasing in the positive difference $\left(x_{j}^{\mathrm{R}}-x_{j}^{\mathrm{L}}\right)$. The figure below sketches out an example where the voter chooses L only because of L's valence advantage, with the contribution of valence highlighted in blue.

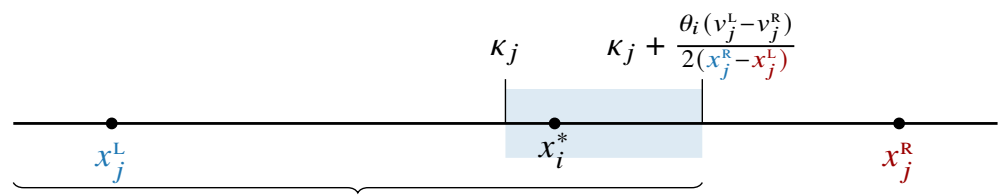

Voter type $x_{i}^{*}$ that votes Democrat (with valence)

(without valence)

Valence as Clarity of Ideal Points We can also consider how uncertainty factors into this decision by treating the candidate position $x_{j}^{a}$ as a random variable. Let

$$
\mathbb{E}\left(x_{j}^{a}\right)=\mu_{j}^{a}, \quad \operatorname{Var}\left(x_{j}^{a}\right)=\eta_{j}^{a}>0
$$


Then the voter's expected utility from party $a, \mathbb{E}\left(U_{i}\left(x_{j}^{a}, y_{j}^{a}\right)\right)$, becomes

$$
\begin{aligned}
& -\mathbb{E}\left(x_{j}^{a}-x_{i}^{*}\right)^{2}+\theta_{i} v_{j}^{a} \\
& =-\mathbb{E}\left(x_{j}^{a}-\mu_{j}^{a}+\mu_{j}^{a}-x_{i}^{*}\right)^{2}+\theta_{i} v_{j}^{a} \\
& =-\underbrace{\mathbb{E}\left(x_{j}^{a}-\mu_{j}^{a}\right)^{2}}_{=\eta_{j}^{a}}-\mathbb{E}\left(\mu_{j}^{a}-x_{i}^{*}\right)^{2}+2 \mathbb{E}\left(\left(x_{j}^{a}-\mu_{j}^{a}\right)\left(\mu_{j}^{a}-x_{i}^{*}\right)\right)+\theta_{i} v_{j}^{a} \\
& \left.=-\eta_{j}^{a}-\mathbb{E}\left(\mu_{j}^{a}-x_{i}^{*}\right)^{2}+2(\underbrace{\operatorname{Cov}\left(\left(x_{j}^{a}-\mu_{j}^{a}\right),\left(\mu_{j}^{a}-x_{i}^{*}\right)\right)}_{=0}+\underbrace{\mathbb{E}\left(x_{j}^{a}-\mu_{j}^{a}\right)}_{=0} \mathbb{E}\left(\mu_{j}^{a}-x_{i}^{*}\right))\right)+\theta_{i} v_{j}^{a} \\
& =-\underbrace{\mathbb{E}\left(\mu_{j}^{a}-x_{i}^{*}\right)^{2}}_{\text {Spatial }}+\underbrace{\theta_{i} v_{j}^{a}-\eta_{j}^{a}}_{\text {New Valence }}
\end{aligned}
$$

Therefore, a large variance $\eta_{j}^{a}$ can be interpreted as having the opposing effect as high valence $\theta v_{j}^{a}$. In other words, high uncertainty in policy position effectively lowers valence.

Multiple Offices Thus far, I have limited the exposition to a case where a voter makes one office, rather than voting on the long ballot. To make the extension straightforward, we will fix the office at the top of the ticket to be contested by candidates who are polarized and equally matched in valence. Vote choice is now a function of the relative difference between candidates, not offices.

In the figure below, we show three cases: the first case repeats the single-office above, which can be thought of as a local office. In the second case, we introduce a "national" office in $j=1$ where candidates are equally polarized as in the local office but the candidate in the local office $j=2$ has a valence advantage.

Voter ideology $x_{i}^{*}$ remains the same across offices because the voter is voting for two offices in the same ballot. As before, the tickmark is the cutpoint between candidates $(\kappa)$ and the blue region $\left[0, \frac{\theta\left(v_{j}^{\mathrm{L}}-v_{j}^{\mathrm{R}}\right)}{2\left(x_{j}^{\mathrm{R}}-x_{j}^{\mathrm{L}}\right)}\right]$ is all the possible values of $x_{i}^{*}$ under which he will vote for the Democratic candidate. 
1. Crossing the party line: polarized parties with Democrat valence advantage

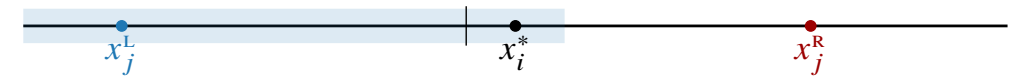

2. Ticket Splitting: Democrat in local office has valence advantage

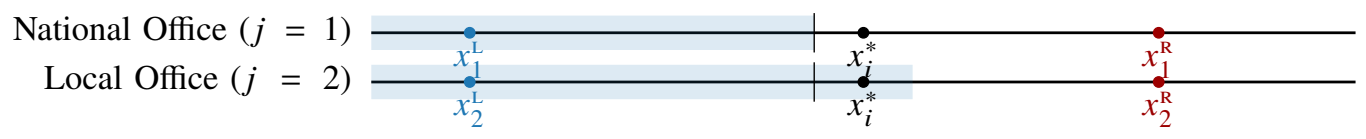

3. Ticket Splitting: In addition to 2, local Democrat is more moderate

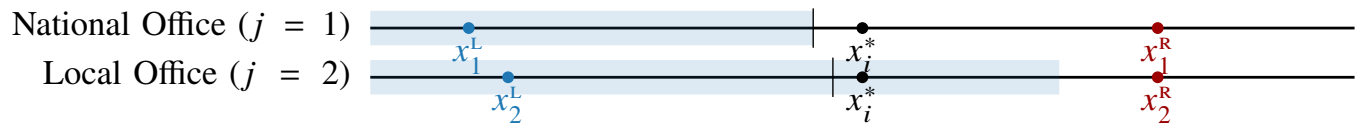

The figure reinforces the point that ticket splitting for a candidate $a$ is increasing in the valence advantage of candidate $a$ and decreasing in the degree of convergence between the two candidates.

In addition, recall that uncertainty about candidate $b$ 's position also effectively enters the decision rule as negative valence for candidate $b$. This implies that if candidate $a$ is more well-known than candidate $b$ in a local office - perhaps through news coverage, advertising, incumbency then ticket splitting will also drawn towards candidate $a$. All this can happen even if voters care equally about party across all offices ( $\theta$ is constant across offices) and candidate's positions were nationalized ( $x_{j}^{\mathrm{L}}$ is constant for all $j$, and the same for $x_{j}^{\mathrm{R}}$ ). 


\section{Appendix B: Data Construction}

Subsection B.1 describes the dataset construction. Subsection B. 2 provides some images of the voting machine used in this paper. Subsection B.4 describes the search specifications used to collect the number of newspaper article hits for a given candidate. Subsection B.5 describes the data collection procedure and coverage for campaign finance data, and Subsection B.6 describes how both the newspaper measures and campaign finance data are summarized to form the values used in the regressions.

\section{B.1 Data Construction}

The final dataset I analyze is in wide-form, with one observation for a given voter in one South Carolina election. I compile this dataset in the following steps.

1. I first process the set of raw cast vote records to standardize the names of offices across precincts. While the state commission oversees elections for all offices, county board of elections apparently finalize their ballots separately. This leads to variations in spelling for offices, even statewide ones.

2. Second, I identify the affiliated party of voted candidates using a separate roster of certified candidates. Although party information is presented in each touchscreen to the voter, only the chosen candidate's name appears in the log. I merge the party affiliation and incumbency status to each name chosen.

One of the more difficult tasks in data processing is to determine which races were available to which voters' ballots, and whether or not the race was contested. The combination of different legislative, school, and special purpose districts leads to many different ballot styles. Each entry in the logs contain a precinct identifier as well as a ballot style identifier unique to each precinct. Although there are around 2,000 to 2,200 precincts in each general election, there are at least 5,000 different ballot styles.

3. To infer the layout of each style, I aggregate the individual logs from the bottom-up. For each precinct and ballot style combination, I tabulate the votes cast for each candidate. When working with contests for offices that held elections for only a subset of voters, I denote that this office did not exist for a given precinct or ballot style if no voter in that set cast a vote for the office. This way, I distinguish abstentions from the lack of existence of the contest.

One side-effect of this procedure is that absentee votes are not counted, because the voting machine codes them with a virtual precinct at the county-level, thereby effectively erasing 
information about the precinct of the absentee ballot. Until 2018, South Carolina voters had to be over 65 or have an "excuse" for not be able to vote on election day to apply for an absentee ballot. In the five general elections studied here, 17.7 percent of the 8.4 million ballots cast were absentee ballots.

4. I then aggregate votes at the district level, and declare a district as contested if votes for both the Republican and Democrat exist.

\section{B.2 The iVotronic Voting Machine}

Figure B1 shows images displayed in the ES \& S iVotronic. All South Carolina machines use the same make of machine, and have similar displays.

Offices are usually placed in the order of federal, state, county, local non-partisan races, and referendums. Within each contest, candidates are always ordered in alphabetical order of their party. For example, the Democratic candidate is always placed before the Republican candidate.

\section{B.3 Cast Vote Records from Other States}

In addition to the entire data from South Carolina, I analyze cast vote records from three other states. The overall split ticket rates in these states are presented in Appendix Section D.1.

Maricopa County, Arizona Maricopa county includes the city of Phoneix and collected over 2 million votes in the 2020 Presidential election (for comparison, the entire state of South Carolina had roughly 2.5 million votes in the same election). Maricopa county overlaps with all but one of Arizona's congressional districts, and 13 contested state senate districts. However, being only a single county, it has fewer candidate-level variation in county-level offices. The county uses a Dominion voting machine to record its ballots, and I parse the JSON output of this file into a tabular format.

Maryland For data on Maryland, I use statewide cast voter records from all four general elections 2016-2022. These cast vote records were acquired by Jonathan Robinson. Each election year includes about 2-2.7 million voters, amounting to 9.6 million voters across the four elections. Maryland's data comes from a ES\&S DS200 machine that exports the cast vote record into a spreadsheet where each row represents a page of the ballot. A small fraction of partisan offices are eliminated from the analysis because they fall on the second page of the ballot and cannot be connected with the voter's first page. Maryland's export system also includes most of its Write-in votes by a scanned image, which I must discard when reading in the file. This means that the write-in vote is undercounted in the Maryland analysis. 
Palm Beach County, Florida I use the contested statewide or countywide races in Palm Beach County Florida, taken from the replication dataset in Herron and Lewis (2007). After subsetting to the five contested congressional districts that intersect with the county, this amounts to over 350,000 votes. These data are from an earlier time period than the one studied in this paper. The electorate also exhibited high levels of ticket splitting in state and local offices. 
Figure B1: Samples of the iVotronic Touch Screen
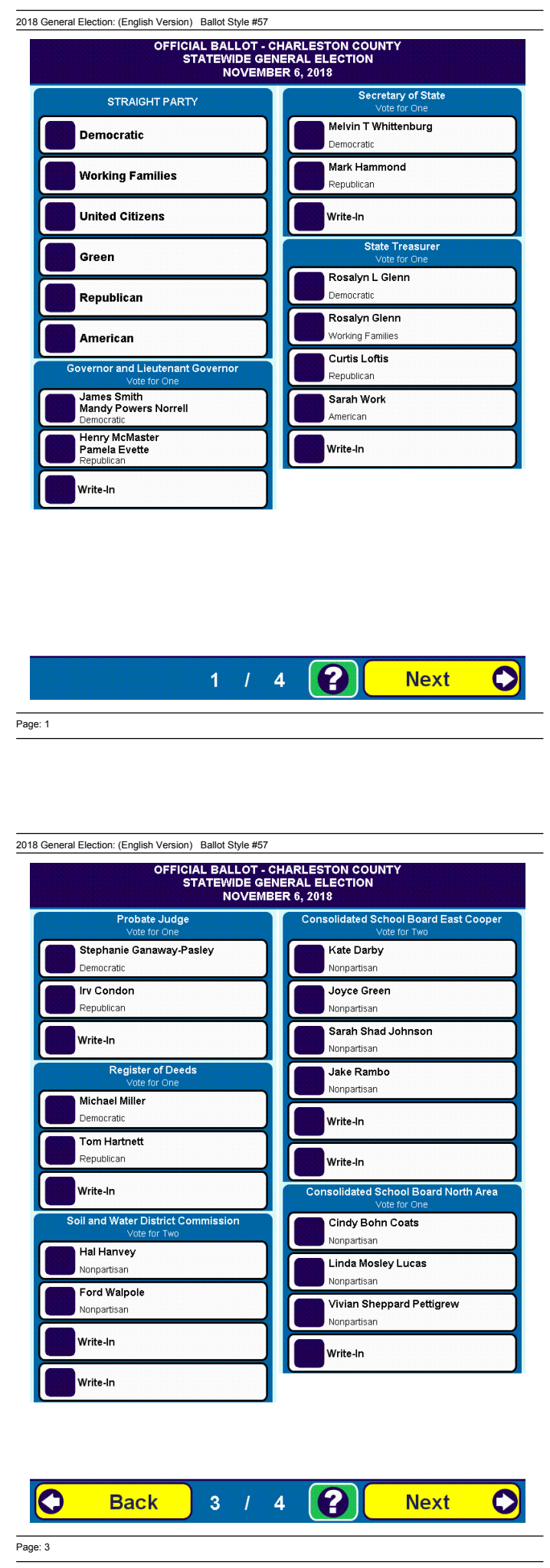
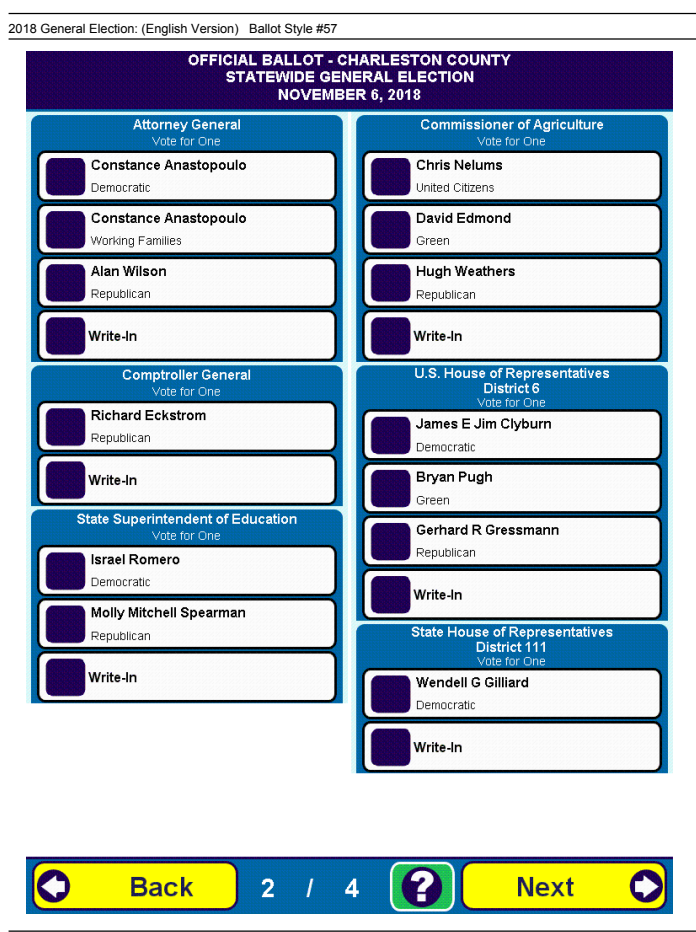

Page: 2

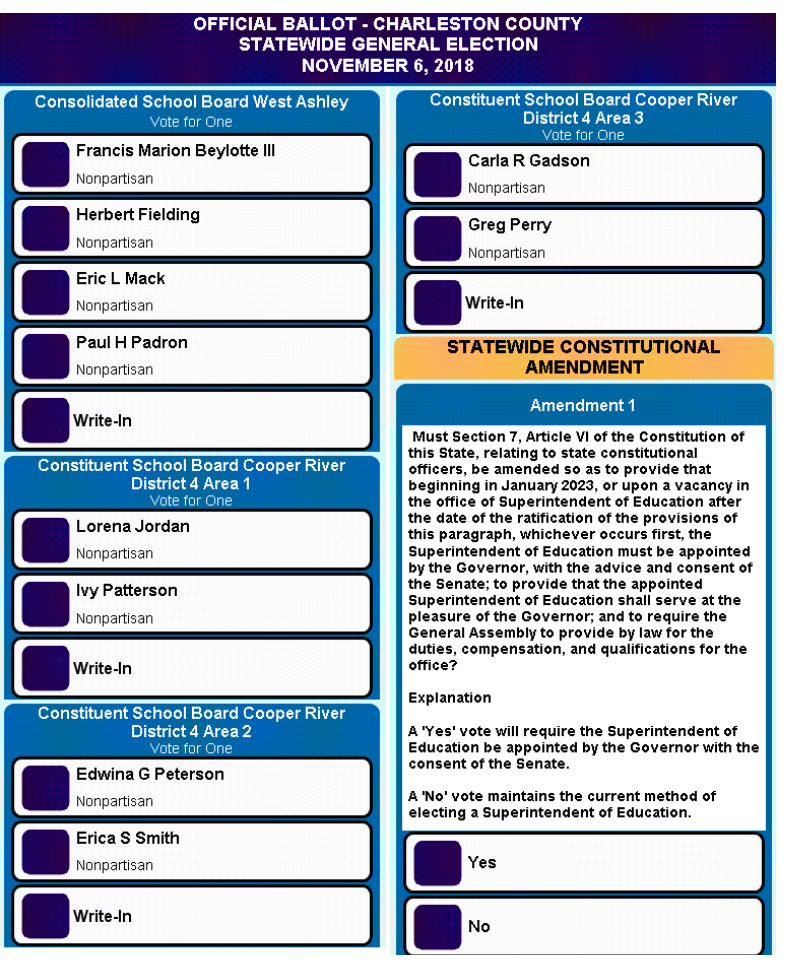

Note: Figures show screen images as they are displayed on the iVotronic. The first question shows the party lever question and the last question shows a ballot measure. This example comes from a particularly short ballot style in Charleston County in 2018, in which all contests fit in four screens. These choices are followed by a set of confirmations. 


\section{B.4 Data on Newspaper Mentions}

For a measure of name familiarity I compute the number of state newspaper articles that mention the candidate's name.

- I search the 71 newspapers in South Carolina available in NewsLibrary.com. ${ }^{13}$ NewsLibrary is one of the largest repositories of state and local news. In contrast, Lexis-Nexis has records for only 4 South Carolina state newspapers during 2010-2018.

- I used the length of the office's term ending the day before the election. For example, for U.S. Senate candidates running against each other in the November 6, 2018 election, I search the dates November 5, 2012 to November 5, 2018. For U.S. House candidates I use a twoyear timeframe. I do not include election day to prevent biasing counts towards the eventual winner.

- I search the official name on the ballot. In case of middle name or first name initials, I also include a version that removes the initial. For example, for "Nikki R Haley", I search for the term ('Nikki R Haley'') OR ('Nikki Haley'').

- I generally do not restrict to specific election-related or office-related terms, with the following exceptions: County Council members, Sheriffs, and Probate Judge searches are further restricted by the county of the office. This measure, then, aims to captures general name recognition with some filters added to prevent miscounting common names (like "David Smith") as mentions of candidates.

Contests and candidates with the highest candidate counts are listed in Table B1. In some contests, the number of mentions is lopsided. For example, the former Governor Mark Sanford (R) 13

The papers are: Aiken Standard, Beaufort Today, The Belton \& Honea Path News-Chronicle, The Berkeley Independent, Bluffton Today, Carolina Gateway (Lancaster), Carolina Panorama (Columbia), CBS 13 WBTW (Florence), CBS 7 WSPA (Greenville-Spartanburg), The Center Square South Carolina, Charleston Examiner, Charleston Regional Business Journal, The Cheraw Chronicle, Chester News \& Reporter, Coastal Observer (Pawleys Island), Columbia Examiner, Columbia Regional Business Report, The Columbia Star, Daily Gamecock, The Dispatch (Walterboro), The Eagle-Record (St. George), The Easley Progress, The Edgefield Advertiser, The Gaffney Ledger, The Georgetown Times, The Goose Creek Gazette, Greenville Examiner, The Greer Citizen, GSA Business Report (Greenville), The Hampton County Guardian, Hardeeville Today, The Herald Independent (Winnsboro), HeraldJournal (Spartanburg), The Horry Independent (Conway), The Index-Journal (Greenwood), Island Today (Bluffton), Jasper County Sun Times, The Journal (Seneca), The Journal (Williamston), The Lancaster News, Lowcountry Parent (Charleston), Marion Star \& Mullins Enterprise, The Messenger (Hartsville), Morning News, Morning News (Florence), Moultrie News (Mt. Pleasant), NBC 2 WCBD (Charleston), The Newberry Observer, The News (Kingstree), News \& Post (Lake City), North Augusta Today, Pageland Progressive-Journal, The Patriot, The PeopleSentinel (Barnwell), The Pickens Sentinel, The Post and Courier, The Powdersville Post (Piedmont), Saluda Standard Sentinel, The Sentinel-Progress (Pickens, Easley), South Carolina Business Journal (Columbia), South Carolina Lawyers Weekly, South Strand News (Georgetown), The Star (North Augusta), The Summerville Journal-Scene, The Tiger, The Tiger News, The Tiger Town Observer, The Times and Democrat (Orangeburg), The Union Daily Times, Waccamaw Times (Murrells Inlet), and The Weekly Observer (Hemingway). 


\section{Figure B2: Newspaper Mentions in Contested Elections.}

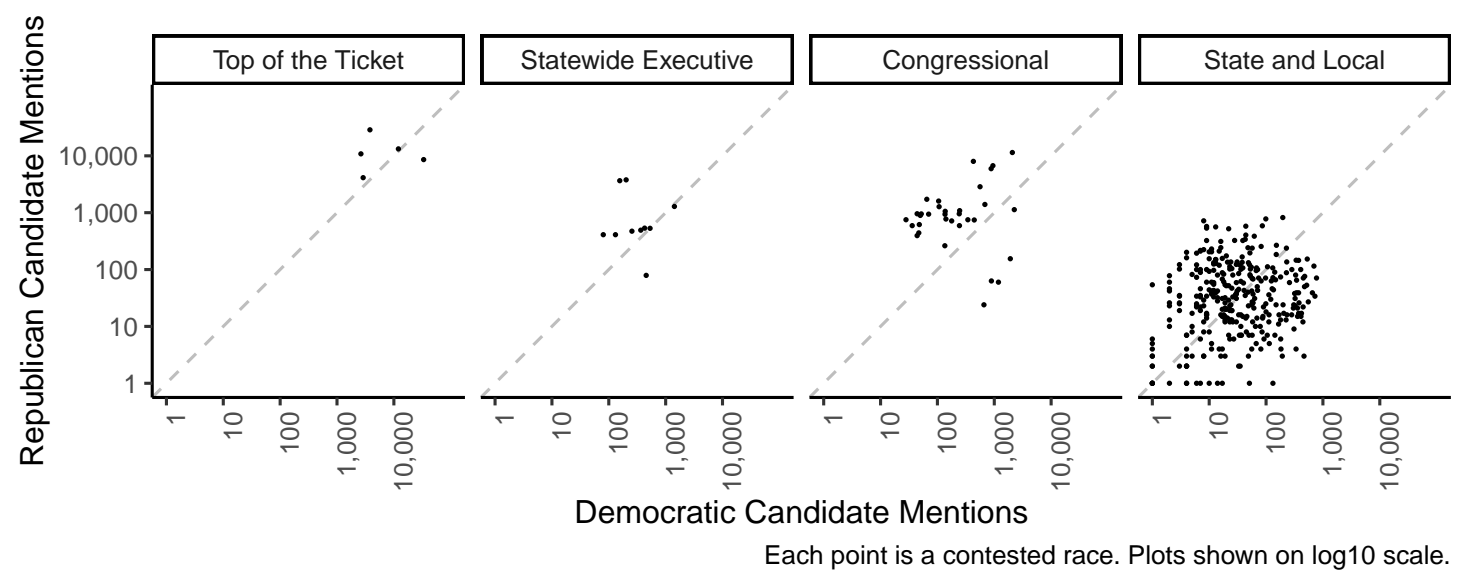

Note: Each point represents the number of South Carolina newspaper articles mentioning the name of the Democrat (horizontal axis) or Republican (vertical axis) candidate in a contested race.

received over 1700 mentions while his opponent received only 64 in the same time period. The advantage measure I construct and ultimately enter into the regressions produces a Republican advantage of 3.3 in this example. Figure B2 shows the distribution of the counts. 
Table B1: Candidate Mentions in Newspapers Scraped. Only some contests, with the highest newspaper counts are shown.

Top of the Ticket

\begin{tabular}{|c|c|c|c|c|c|}
\hline \multirow[b]{2}{*}{ Year } & \multirow[b]{2}{*}{ Office } & \multicolumn{2}{|l|}{ Democrat } & \multicolumn{2}{|c|}{ Republican } \\
\hline & & Name & \# & Name & \# \\
\hline 2012 & President & Barack Obama & 33,384 & Mitt Romney & 8,588 \\
\hline 2014 & Governor & Vincent Sheheen & 3,792 & Nikki R Haley & 28,660 \\
\hline 2016 & President & Hillary Rodham Clinton & 12,021 & Donald J Trump & 13,237 \\
\hline 2018 & Governor & James Smith & 2,633 & Henry McMaster & 10,834 \\
\hline 2010 & Governor & Vincent A Sheheen & 2,882 & Nikki R Haley & 4,129 \\
\hline
\end{tabular}

Congressional

\begin{tabular}{|c|c|c|c|c|c|}
\hline \multirow[b]{2}{*}{ Year } & \multirow[b]{2}{*}{ Office } & \multicolumn{2}{|c|}{ Democrat } & \multicolumn{2}{|c|}{ Republican } \\
\hline & & Name & \# & Name & \# \\
\hline 2014 & US Senate & Brad Hutto & 2,078 & Lindsey Graham & 11,431 \\
\hline 2016 & US Senate & Thomas Dixon & 428 & Tim Scott & 7,991 \\
\hline 2010 & US Senate & Alvin M Greene & 944 & Jim DeMint & 6,707 \\
\hline 2014 & US Senate & Joyce Dickerson & 879 & Tim Scott & 5,945 \\
\hline 2010 & US House & Rob Miller & 561 & Joe Wilson & 2,861 \\
\hline 2010 & US House & John Spratt & 2,247 & Mick Mulvaney & 1,130 \\
\hline 2010 & US House & James E Jim Clyburn & 1,912 & Jim Pratt & 154 \\
\hline 2016 & US House & Dimitri Cherny & 64 & Mark Sanford & 1,721 \\
\hline 2012 & US House & Bobbie Rose & 104 & Tim Scott & 1,601 \\
\hline 2018 & US House & Archie Parnell & 683 & Ralph W Norman & 1,395 \\
\hline
\end{tabular}

State and Local

\begin{tabular}{|c|c|c|c|c|c|}
\hline \multirow[b]{2}{*}{ Year } & \multirow[b]{2}{*}{ Office } & \multicolumn{2}{|c|}{ Democrat } & \multicolumn{2}{|l|}{ Republican } \\
\hline & & Name & $\#$ & Name & \# \\
\hline 2012 & State Senate & Paul Tinkler & 196 & Paul Thurmond & 820 \\
\hline 2012 & State Senate & Robert Rikard & 98 & John Courson & 776 \\
\hline 2012 & Sheriff & Barry Faile & 770 & Scott R Case & 70 \\
\hline 2016 & State Senate & Nikki Setzler & 723 & Brad Lindsey & 33 \\
\hline 2016 & Sheriff & William McCoy & 7 & Barry Faile & 718 \\
\hline 2016 & Sheriff & Alex Underwood & 694 & Richard Smith & 114 \\
\hline 2016 & Sheriff & David H Taylor & 652 & Jeff D Bailey & 38 \\
\hline 2012 & County Council & Jack T Collins & 85 & Joel R Thrift & 587 \\
\hline 2016 & Auditor & Peter J Tecklenburg & 43 & Elizabeth Moffly & 578 \\
\hline 2018 & State House & Marty R Cotton & 8 & Thomas E Tommy Pope & 572 \\
\hline
\end{tabular}




\section{B.5 Data on Campaign Contributions}

Contribution data is collected from official sources but measured with error. These come from two sources, the organization Follow The Money and the South Carolina State Ethics Commission.

For the offices of US House, State Senate, and State House, I drew values curated by Follow The Money (https://followthemoney. org). This organization collects the contributions reported to the FEC and state election commissions, and for each candidate in each election cycle, reports the total campaign contribution a candidate received.

For the offices of Sheriff, Probate Judge, and County Council, I collected data from the state Ethics Commission (https://apps.sc.gov/PublicReporting). These contain all candidate finance disclosure reports a campaign for state office has filed. Candidates can file these reports at any time in the cycle, so when multiple reports I take the most recent value of "Total Contribution for Election Cycle" (including in-kind contributions) no later than the January following the election (all from the appropriate election cycle). I ignore finances listed under the primary election and set the total to zero if no record is found, which is the case in a handful of local races.

Some campaign finance reports in state and local races report zero contributions and zero expenditures. Perhaps those candidates did no fundraising and spent no money on their campaigns. However, state and local parties may have supported the candidate in ways that do not appear on the report, such as booking meeting centers for candidates for multiple offices. Campaign finances are difficult to track in state and local races. This is especially the case in South Carolina, where a 2010 district court case effectively exempted independent political action committees from disclosing their donors, which include party organizations (South Carolina Citizens for Life v. Kenneth $C$. Krawcheck et al.). 


\section{B.6 Summary Statistics for the Valence Advantage}

This subsection formalizes how the measure of the valence advantage is constructed in equation (1).

Incumbency is a binary variable, taking 1 if the Republican candidate is an incumbent and 0 otherwise. This variable is only used in contested races.

Newspaper coverage (measured in number of article hits) and contributions (measured in dollars) are denoted by the continuous variable $v_{c[j]}^{a}$ : the valence measure of candidate $a$ in district $c[j]$. We quantify the Republican advantage for both measures of valence as the natural log of the ratio, specifically

$$
\begin{aligned}
V_{c[j]} & =\log \left(\frac{v_{c[j]}^{\mathrm{R}}+1}{v_{c[j]}^{\mathrm{D}}+1}\right) \\
& =\log \left(v_{c[j]}^{\mathrm{R}}+1\right)-\log \left(v_{c[j]}^{\mathrm{D}}+1\right) .
\end{aligned}
$$

Taking the ratio is appropriate because the relevant comparison is between two candidates competing against each other. Taking the log reduces the impact of outliers and allows coefficients to be interpreted either as an association with a one-unit change in the ratio or a one-unit change in the difference between the logs of the two candidates. Adding one to each value before taking the $\log$ prevents the few candidates that have zero news article hits or report no campaign contributions from causing divide-by-zero errors.

Table B2 provides summary statistics of this measure for each office. Because log values are difficult to interpret substantively, I also present two variations. First, the table also shows the exponentiated version of the summary statistics in the right-hand set of columns. This is approximately equivalent to the actual ratio,

$$
\exp \left(V_{c[j]}\right)=\frac{v_{c[j]}^{\mathrm{R}}+1}{v_{c[j]}^{\mathrm{D}}+1} \approx \frac{v_{c[j]}^{\mathrm{R}}}{v_{c[j]}^{\mathrm{D}}}
$$

Second, the estimates in Figure 3 multiply the regression coefficients estimated with Equation (1) by the standard deviations reported in Table B2. This allows the coefficients to be interpreted as the difference in the outcome associated by a one standard deviation increase in the valence advantage of that office. 
Table B2: Summary Statistics for the Newspaper Coverage and the Fundraising Advantage

Republican Newspaper Coverage Advantage Summary Statistics

\begin{tabular}{|c|c|c|c|c|c|c|c|c|c|c|}
\hline \multirow[b]{2}{*}{ Office } & \multicolumn{5}{|c|}{ Log Values } & \multicolumn{4}{|c|}{ Exponentiated } & \multirow[b]{2}{*}{$\mathrm{N}$} \\
\hline & Mean & 10th & 50 th & 90th & S.D. & Mean & 10th & 50th & 90th & \\
\hline US House & 1.24 & -2.54 & 1.70 & 2.94 & 1.92 & 3.46 & 0.08 & 5.49 & 18.94 & 31 \\
\hline State House & 0.42 & -2.15 & 0.46 & 2.89 & 1.88 & 1.52 & 0.12 & 1.59 & 18.02 & 161 \\
\hline State Senate & -1.32 & -3.29 & -1.41 & 2.09 & 2.23 & 0.27 & 0.04 & 0.24 & 8.10 & 19 \\
\hline County Sheriff & -0.29 & -2.88 & -0.49 & 2.81 & 2.20 & 0.75 & 0.06 & 0.61 & 16.61 & 19 \\
\hline Probate Judge & 0.42 & -0.72 & 0.00 & 1.66 & 1.01 & 1.53 & 0.49 & 1.00 & 5.24 & 19 \\
\hline County Council & -0.30 & -2.66 & -0.46 & 2.43 & 1.96 & 0.74 & 0.07 & 0.63 & 11.37 & 101 \\
\hline
\end{tabular}

Republican Fundraising Advantage Summary Statistics

\begin{tabular}{|c|c|c|c|c|c|c|c|c|c|c|}
\hline \multirow[b]{2}{*}{ Office } & \multicolumn{5}{|c|}{ Log Values } & \multicolumn{4}{|c|}{ Exponentiated } & \multirow[b]{2}{*}{$\mathrm{N}$} \\
\hline & Mean & 10th & 50th & 90th & S.D. & Mean & 10th & 50th & 90th & \\
\hline US House & 1.72 & -0.34 & 1.99 & 4.30 & 2.07 & 5.59 & 0.71 & 7.29 & 73.41 & 31 \\
\hline State House & 0.68 & -2.38 & 0.74 & 3.80 & 2.38 & 1.98 & 0.09 & 2.09 & 44.78 & 161 \\
\hline State Senate & -0.90 & -2.60 & -1.34 & 1.30 & 1.98 & 0.41 & 0.07 & 0.26 & 3.68 & 19 \\
\hline County Sheriff & 0.81 & -1.51 & 0.72 & 3.58 & 2.23 & 2.25 & 0.22 & 2.05 & 35.75 & 19 \\
\hline Probate Judge & 0.32 & -3.05 & 0.44 & 3.02 & 3.96 & 1.38 & 0.05 & 1.56 & 20.56 & 19 \\
\hline County Council & 0.46 & -3.90 & 0.00 & 6.38 & 3.94 & 1.58 & 0.02 & 1.00 & 590.23 & 101 \\
\hline
\end{tabular}

Note: Tables show mean, 10th percentile, median, 90th percentile, standard deviation, and sample size for the respective measure by office. Each observation is measured at the contest level. Exponentiated versions approximate the quantity in their original ratio form. 


\section{Appendix C: Elections in South Carolina}

\section{C.1 Historical Trends in South Carolina Elections}

Table C3 summarizes the election results from the past four decades in South Carolina. State legislative results (-2016) come from Klarner (2021), and countywide executive results between 19801996 come from Lublin (2007) and were generously provided by David Lublin. The figure shows a consistent conversion of Democratic officeholders to Republican ones. Congress realigned earlier than county offices. This is consistent with findings in Aldrich (2000).

Table C3: Party Choice from Election Returns, South Carolina 1980-2018

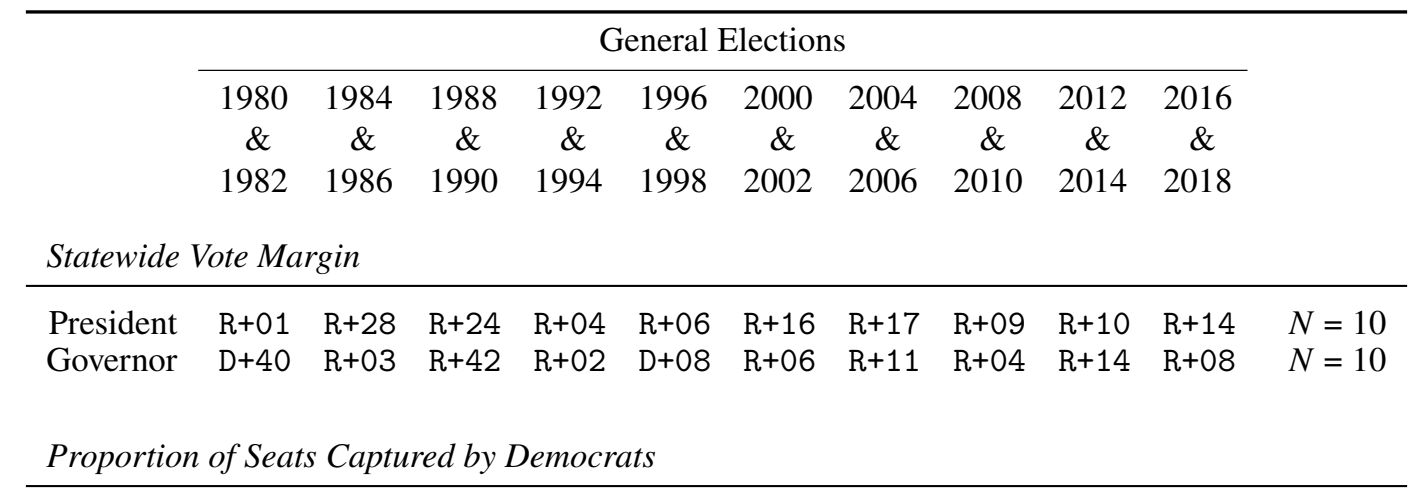

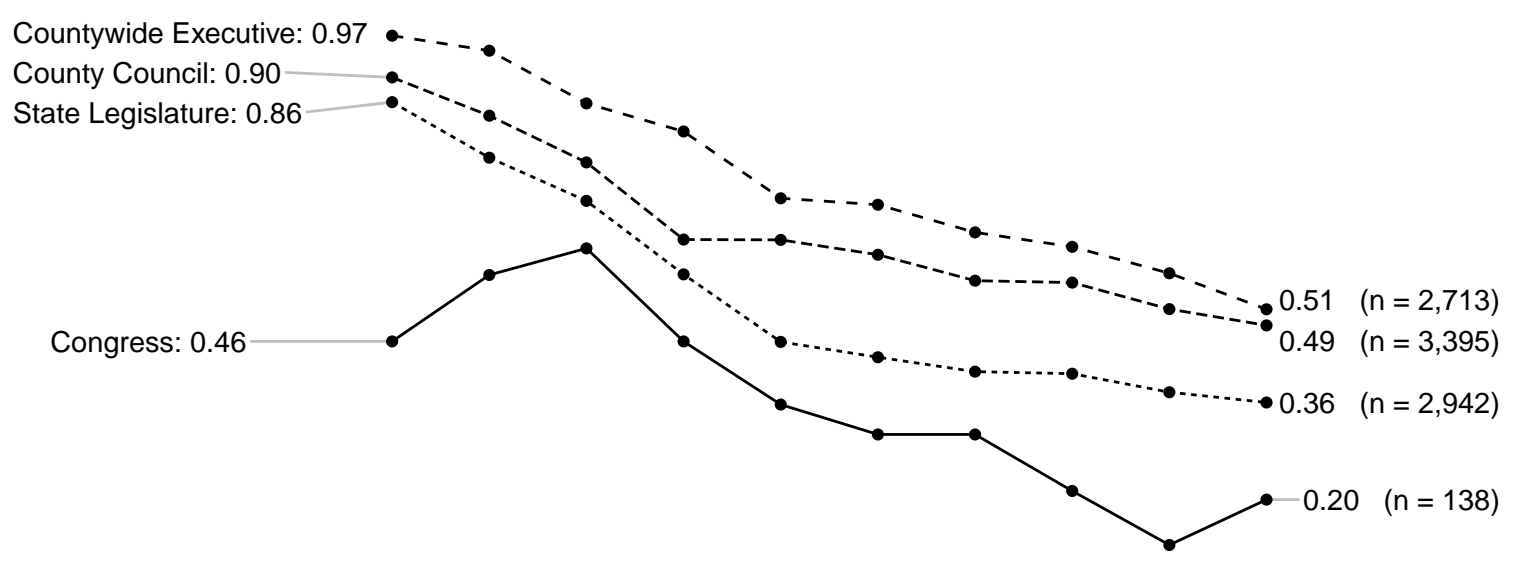

Note: President and Governor entries indicate the winning party and win margin in percentage points. The lineplot values are aligned with the table and each line's endpoints show values at the first and last set of elections. Countywide Executive offices are the six offices of sheriff, probate judge, clerk of court, auditor, treasurer, and coroner, all of which are elected countywide. The last column indicates the total number of contests comprising each row. 


\section{C.2 Elections and Offices Covered}

Table C4 shows the extent of the iVotronic data examined in this article. I show the offices up for election, the number of contested races, and the number of precincts and voters for each general election year.

\section{Table C4: Extent of Elections Analyzed through Cast Vote Records}

\begin{tabular}{|c|c|c|c|c|c|c|}
\hline & \multicolumn{5}{|c|}{ General Elections } & \multirow[b]{2}{*}{ Total } \\
\hline & 2010 & 2012 & 2014 & 2016 & 2018 & \\
\hline \multicolumn{7}{|c|}{ Availability of Contested Statewide Races } \\
\hline President & & $\bar{\checkmark}$ & & $\checkmark$ & & \\
\hline Governor & $\checkmark$ & & $\checkmark$ & & $\checkmark$ & \\
\hline U.S. Senate & $\checkmark$ & & $\checkmark$ & $\checkmark$ & & \\
\hline Attorney General & $\checkmark$ & & $\checkmark$ & & $\checkmark$ & \\
\hline Secretary of State & $\checkmark$ & & $\checkmark$ & & $\checkmark$ & \\
\hline State Superintendent & $\checkmark$ & & $\checkmark$ & & & \\
\hline \multicolumn{7}{|c|}{ Number of Contested District Races } \\
\hline US House & 6 & 5 & 5 & 7 & 7 & 30 \\
\hline State Senate & 0 & 11 & 0 & 7 & 1 & 19 \\
\hline State House & 34 & 20 & 29 & 32 & 44 & 159 \\
\hline County Sheriff & 1 & 3 & 0 & 14 & 1 & 19 \\
\hline Probate Judge & 6 & 2 & 4 & 0 & 7 & 19 \\
\hline County Council & 26 & 8 & 20 & 27 & 19 & 100 \\
\hline \multicolumn{7}{|l|}{ Sample Size } \\
\hline Counties & 43 & 45 & 46 & 46 & 46 & 226 \\
\hline Precincts & 2,001 & 2,115 & 2,216 & 2,232 & 2,245 & 10,809 \\
\hline Voters & $1,101 \mathrm{k}$ & $1,501 \mathrm{k}$ & $1,058 \mathrm{k}$ & $1,570 \mathrm{k}$ & $1,414 \mathrm{k}$ & $6,644 \mathrm{k}$ \\
\hline
\end{tabular}

Note: Numbers are from data after pre-processing, detailed in Appendix C. The number of voters in each election are shown in the last row, thousands. Two counties from 2010 and one county from 2012 is missing from the files released by the state election commission. 


\section{Appendix D: Additional Findings}

Subsection D.1 shows additional descriptive statistics by office and election, Subsection D.2 shows the distribution of proportion straight ticket with and without the people who pulled the party lever, Subsection D.3 shows additional regression results for the incumbency advantage, and Subsection D.4 shows estimates of overtime change in straight ticket voting.

\section{D.1 Split Ticket Voting by Election, Party, and Office.}

Figure D3 shows the breakdown of straight ticket, split ticket, third party voting and roll-off by office, election, and party choice at the top of the ticket. The top of the ticket is indicated by the text at the top of the column. These sets of figures serve as a more granular version than Figure 1 and show sample sizes. 
Figure D3: Party Loyalty on the Long Ballot - South Carolina. Each subplot shows the vote choice composition for a contested down-ballot office. Colors indicate Republican (red), Democrat (blue), third-party or write-in (yellow), and roll-off/undervote (gray). White number shows the pairwise straight-ticket rate. $N$ indicates the number of ballots analyzed in each cell in thousands, and indicates the number of voters in contested districts for that office.

\begin{tabular}{cc}
2012 \\
\hline $\begin{array}{c}\text { Obama } \\
\text { voters }\end{array}$ & $\begin{array}{c}\text { Romney } \\
\text { voters }\end{array}$
\end{tabular}

\begin{tabular}{cc}
\multicolumn{2}{c}{2016} \\
\hline Clinton & Trump \\
voters & voters
\end{tabular}

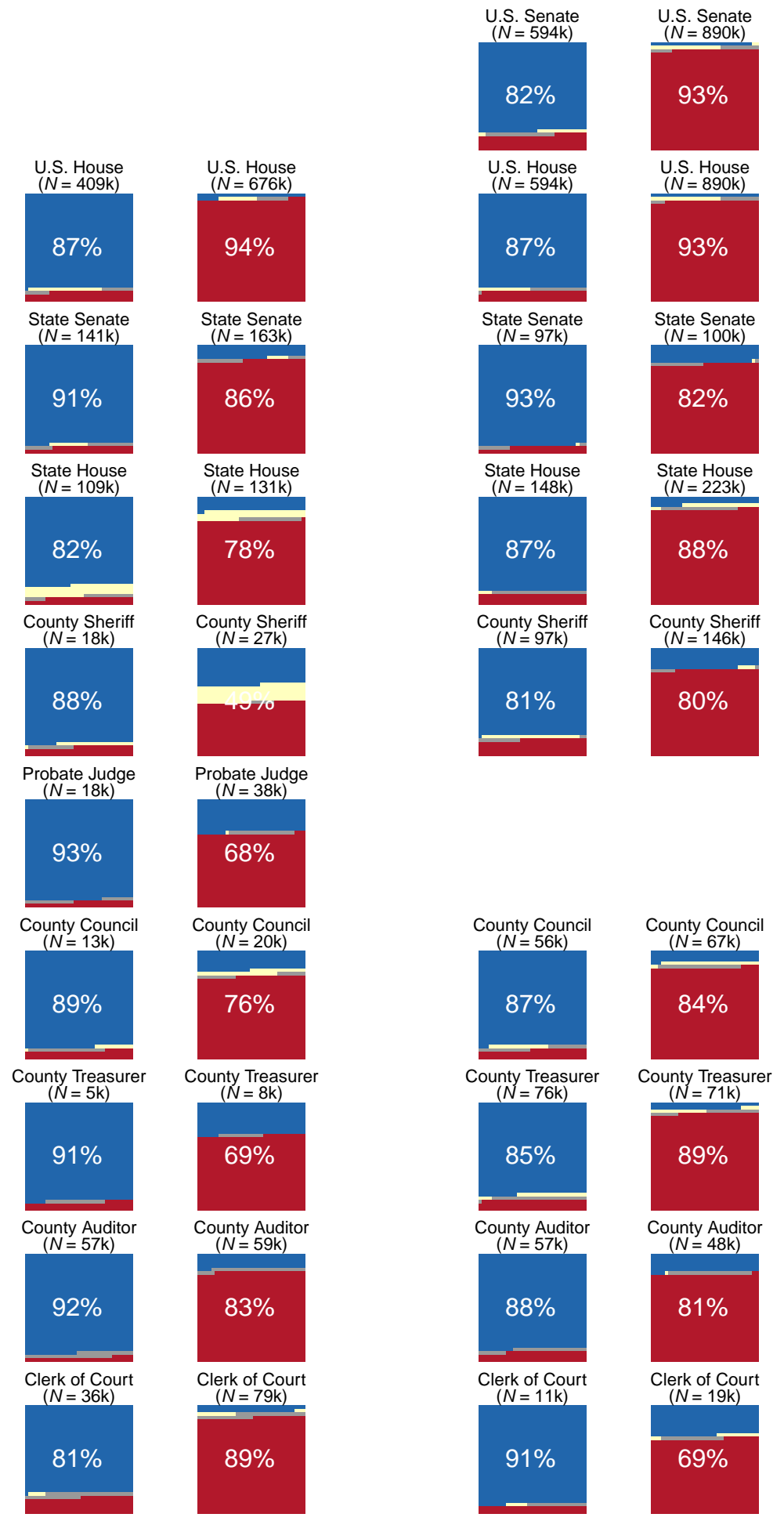


(Figure D3 continued. 2010 and 2014 use the U.S. Senate Election as reference, and 2018 uses the Governor election as reference since there was no Senate election. The U.S. Senate Special Election in 2014 was won by Tim Scott (R), who is Black.)

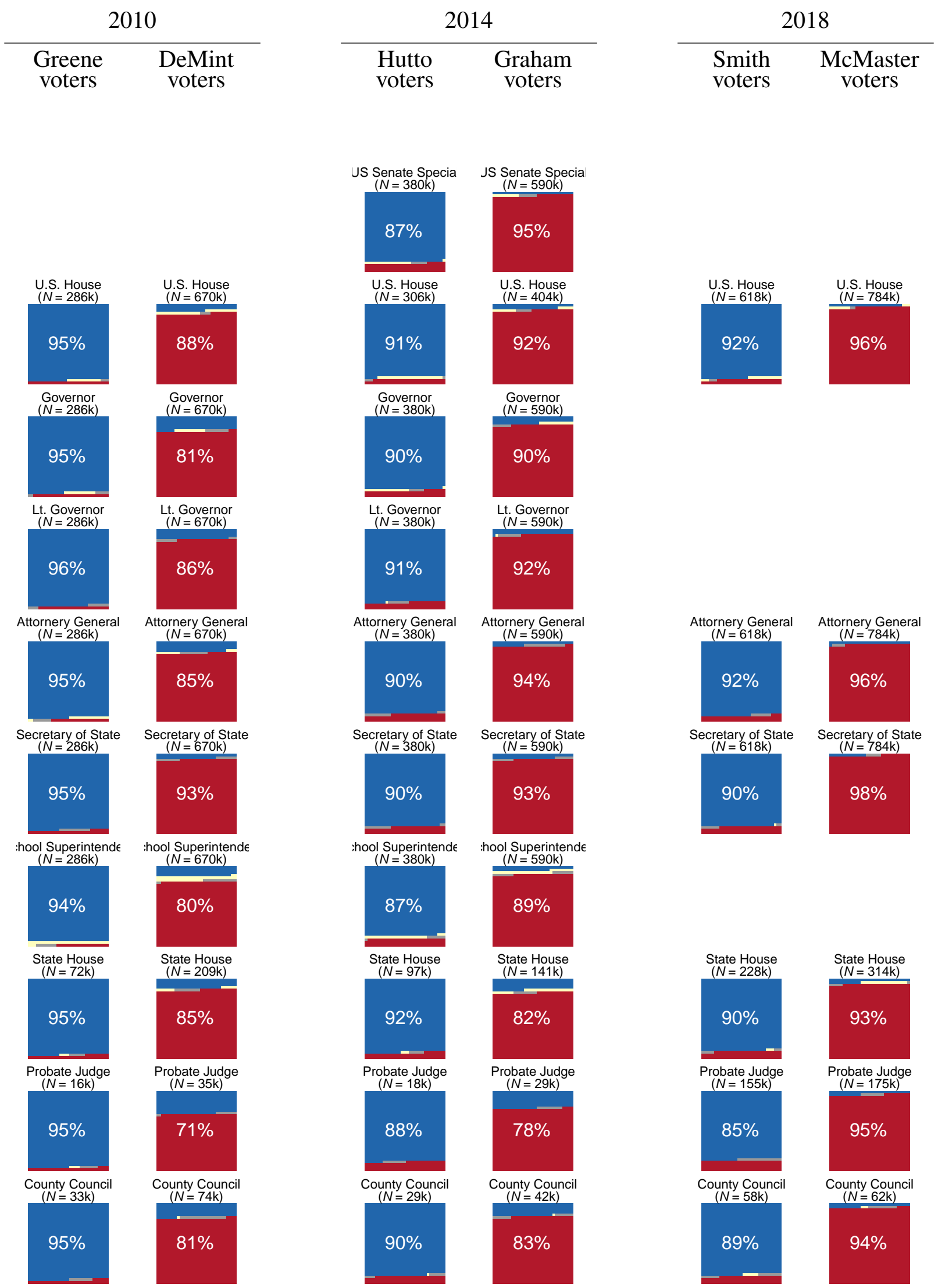


Figure D4: Party Loyalty on the Long Ballot - Maryland. See Figure D3 for legend. 2018 and 2022 results use the U.S. Senate race as the reference election.

\begin{tabular}{cc}
\multicolumn{2}{c}{2016} \\
\hline $\begin{array}{c}\text { Clinton } \\
\text { voters }\end{array}$ & $\begin{array}{l}\text { Trump } \\
\text { voters }\end{array}$
\end{tabular}

\begin{tabular}{cl}
\multicolumn{2}{c}{2020} \\
\hline Biden & Trump \\
voters & voters
\end{tabular}
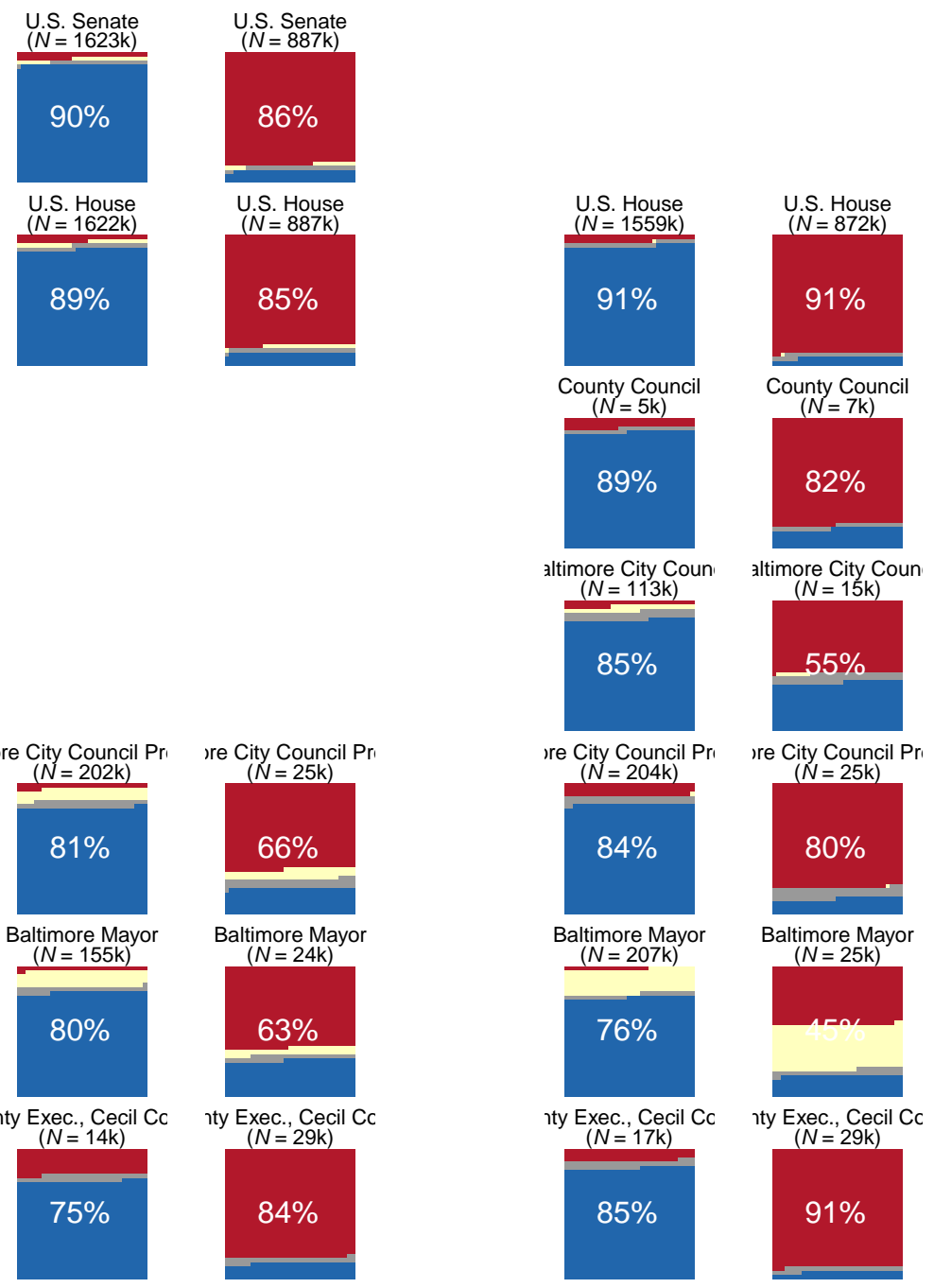


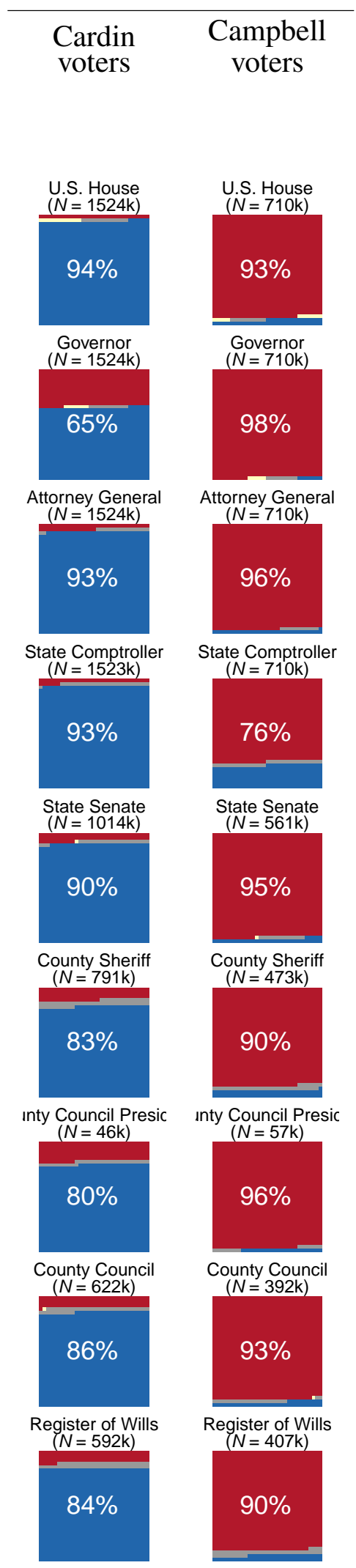

$\begin{array}{cc}\begin{array}{c}\text { Van Hollen } \\ \text { voters }\end{array} & \begin{array}{c}\text { Chaffee } \\ \text { voters }\end{array}\end{array}$
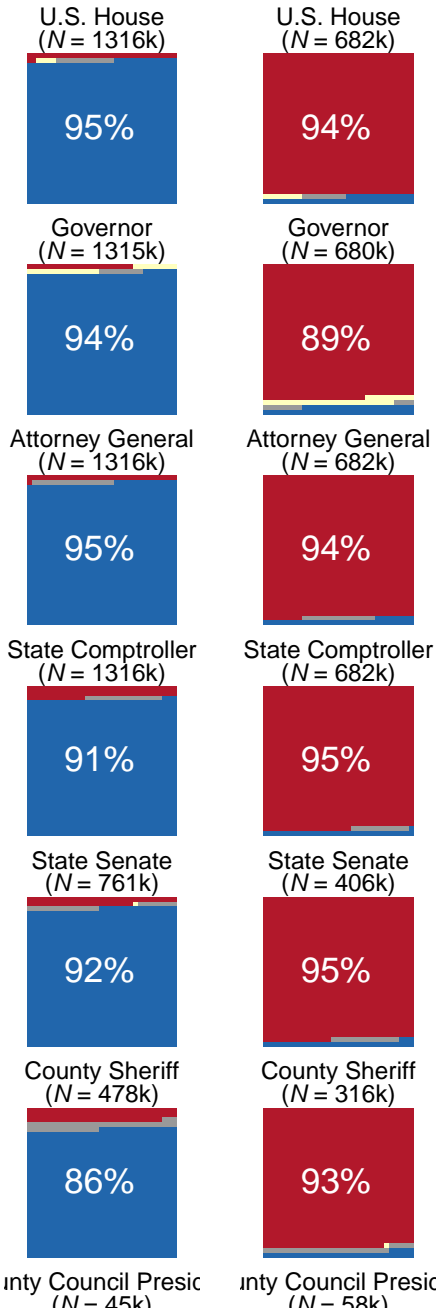

Council Presic
$(N=45 \mathrm{k})$
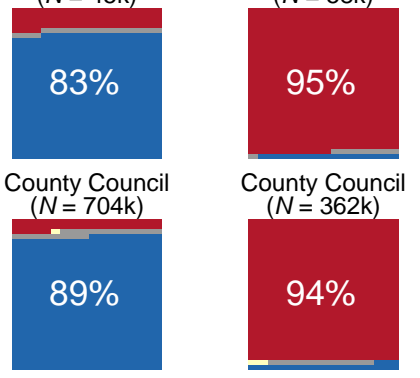

County Council

Register of Wills $(N=486 k)$
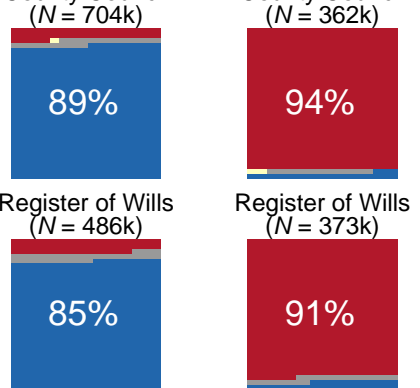

Register of Wills $(N=373 \mathrm{k})$

Clerk of Court $(N=457 \mathrm{k})$

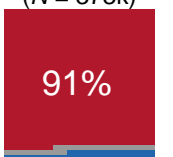

$88 \%$ Clerk of Court
$(N=327 \mathrm{k})$

$92 \%$ 
Figure D5: Party Loyalty on the Long Ballot - Maricopa, Arizona. See Figure D3 for legend. This data analyzes all Maricopa voters who cast a ballot for Biden or Trump. The U.S. Senate race in this election was between Mark Kelly (D) and Martha McSally (R).

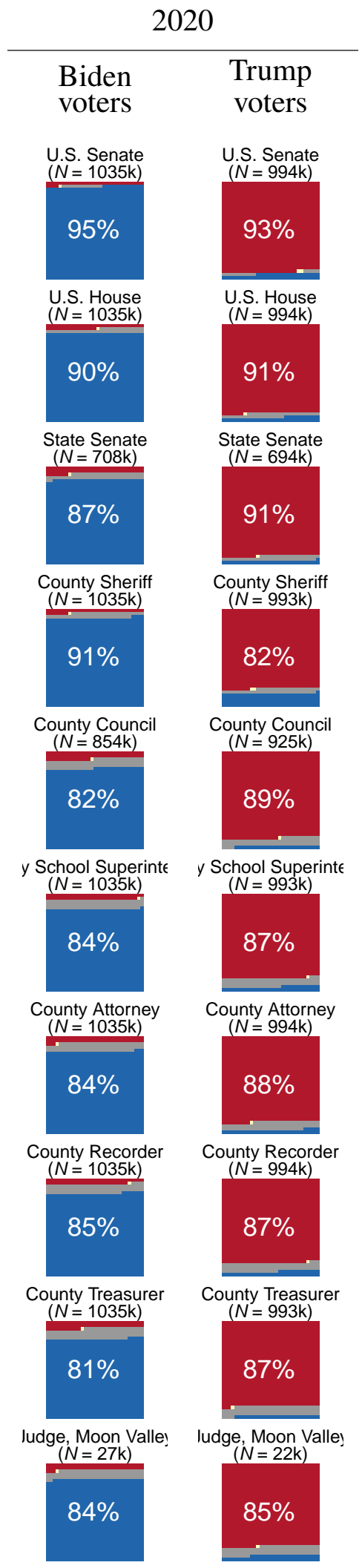


Figure D6: Party Loyalty on the Long Ballot - Palm Beach County, Florida. See Figure D3 for legend.

\begin{tabular}{cc}
\multicolumn{2}{c}{2000} \\
\hline Gore & Bush \\
voters & voters
\end{tabular}

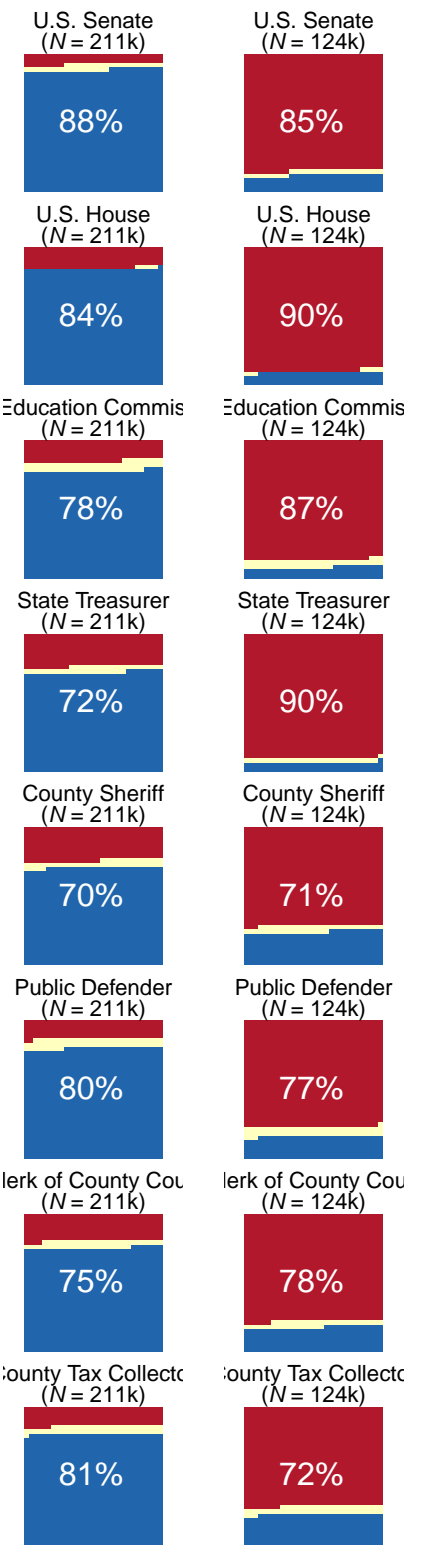




\section{D.2 Distribution of Ticket Splitting Rates}

This section summarizes the South Carolina across offices for summary statistics, show the proportion of a single voter's ballot that is a straight ticket. This rate clearly depends on the number of contested offices on each voter's ballot. Therefore, Table D5 (left half) disaggregates the voters by the number of two-party contested contests featured on the voter's ballot. The

The right panel computes these statistics only among those who did not select the Straight Ticket Option explained in the main text. To avoid confusion of terms, I refer to this latter option as using the party lever, a phrase originating from the era when voters pulled physical levers on voting machines. Among the half of the electorate that opted out of the party lever, the prevalence of straight ticket voters is about 10 to 30 percentage points less than the full sample.

Table D5: Straight Ticket Rates by Number of Contested Contests

\begin{tabular}{|c|c|c|c|c|c|c|}
\hline \multirow[b]{3}{*}{ Contested Races } & \multirow{2}{*}{\multicolumn{3}{|c|}{$\begin{array}{c}\text { (i) } \\
\text { All Voters }\end{array}$}} & \multirow{2}{*}{\multicolumn{3}{|c|}{$\begin{array}{c}\text { (ii) } \\
\text { Voters opting out of the Party Lever }\end{array}$}} \\
\hline & & & & & & \\
\hline & Straight & Distribution & $N$ & Straight & Distribution & $N$ \\
\hline 3 & 0.80 & $-\quad-$ & $1,093 \mathrm{k}$ & 0.66 & $-\quad-$ & $570 \mathrm{k}$ \\
\hline 4 & 0.82 & $---=$ & $1,295 \mathrm{k}$ & 0.64 & $---a$ & $559 \mathrm{k}$ \\
\hline 5 & 0.77 & ---- & $732 \mathrm{k}$ & 0.56 & $----\square$ & $322 \mathrm{k}$ \\
\hline 6 & 0.75 & 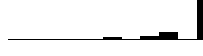 & $299 k$ & 0.52 & $-\ldots$ & $134 \mathrm{k}$ \\
\hline 7 & 0.64 & & $965 \mathrm{k}$ & 0.39 & $-\ldots$ & $505 \mathrm{k}$ \\
\hline 8 & 0.65 & - & 897k & 0.42 & $\ldots$ & $471 \mathrm{k}$ \\
\hline $9-12$ & 0.62 & & $380 \mathrm{k}$ & 0.35 & $\ldots$ & $199 k$ \\
\hline Total & & & $5,661 \mathrm{k}$ & & & $2,760 \mathrm{k}$ \\
\hline
\end{tabular}

Note: Each proportion shows the fraction of voters who voted for the same party for all contested races on their ballot, with number of voters $(N)$ counted in thousands. Each set of black bars is a histogram, which shows the distribution of a person's vote for a favored party as a fraction of the contested races on their ballot. In all histograms, both axes range from 0 to 100 percent; therefore the height of the rightmost bar corresponds to the "Straight" proportion.

\section{D.3 The Valence Advantage: Additional Results}

In this set of results, we estimate the following equation for each voter $i$ making a choice for race $j$ on their ballot:

$$
R_{i j}=\alpha+\beta_{0} \mathrm{D}_{i}+\beta_{1} \mathrm{~V}_{c[i j]}^{\mathrm{inc}}+\beta_{2} \mathrm{~V}_{c[i j]}^{\text {news }}+\beta_{3} \mathrm{~V}_{c[i j]}^{\text {money }}+\varepsilon_{i, c[i j]}
$$


Here the binary outcome $R_{i j}$ is 1 if individual $i$ votes for the Republican candidate in a contested election for an office $j$, and 0 if she votes for another party's candidate, writes in, or abstains. This choice of the outcome variable is slightly more convenient to present in table setting, because the expected direction of the party and valence variables are clear. The predictor variables follow equation (1) in the main text; the difference here is that we now enter the valence terms at once. We present the main results, by office, in Table D6.

Figure D7 shows predicted probabilities from logit versions of the linear probability model presented in Table D6. This better shows how the valence advantage manifests in the outcome variable at values of the control variable $D_{i}$ between 0 and 1 . Table D7 conducts similar regressions as that of Table D6 but removing third party vote and roll-off from the data.

Figure D7: Predicted Probabilities from Logit Regressions for Table D6.
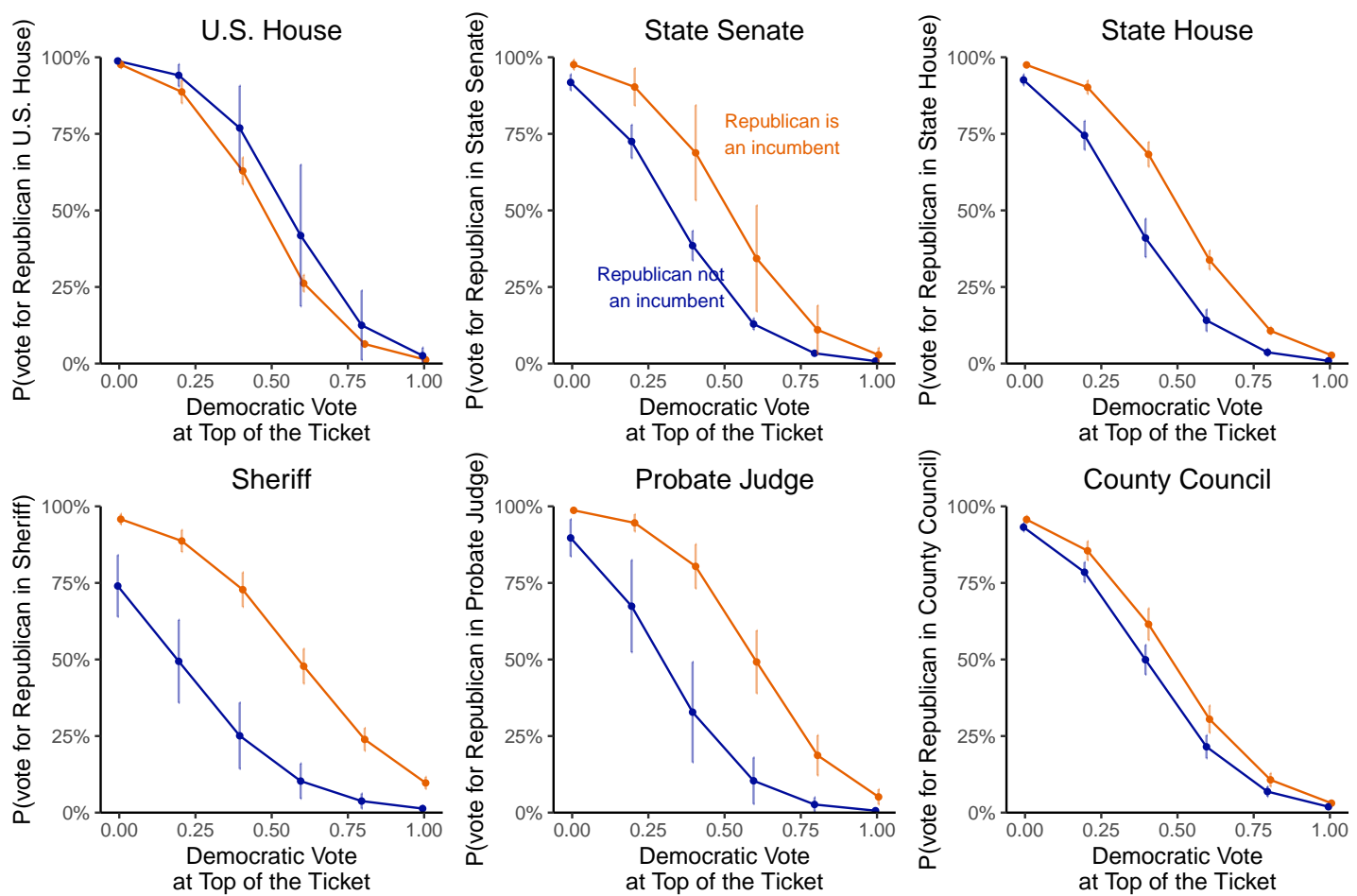

Note: Each panel shows predicted probabilities from regressions of the same specification as the top panel of Table D6, but using a logit regression instead of a linear probability model. I show predicted probabilities along equidistant values of the Democratic top of the ticket vote fraction (on the horizontal axis), separately for party affiliation of the incumbent (orange for Republican, blue for Democrat), and other predictors held at their mean. 95 percent confidence intervals are shown for each point. 
Table D6: Valence Advantages in State and Local Elections

(a) Contested Contests with an Incumbent

\begin{tabular}{|c|c|c|c|c|c|c|}
\hline & \multicolumn{6}{|c|}{ Outcome: Vote for Republican for } \\
\hline & $\begin{array}{l}\text { U.S. } \\
\text { House }\end{array}$ & $\begin{array}{c}\text { State } \\
\text { Senate }\end{array}$ & $\begin{array}{l}\text { State } \\
\text { House }\end{array}$ & Sheriff & $\begin{array}{l}\text { Probate } \\
\text { Judge }\end{array}$ & $\begin{array}{l}\text { County } \\
\text { Council }\end{array}$ \\
\hline Republican Incumbent & $\begin{array}{c}-0.035 \\
(0.03)\end{array}$ & $\begin{array}{l}0.11 * \\
(0.05)\end{array}$ & $\begin{array}{c}0.048 * \\
(0.02)\end{array}$ & $\begin{array}{l}0.26^{*} \\
(0.05)\end{array}$ & $\begin{array}{l}0.16^{*} \\
(0.03)\end{array}$ & $\begin{array}{c}0.037 * \\
(0.02)\end{array}$ \\
\hline Republican Newspaper Coverage Advantage & $\begin{array}{l}0.0039 \\
(0.009)\end{array}$ & $\begin{array}{r}-0.015 \\
(0.01)\end{array}$ & $\begin{array}{c}-0.0043 \\
(0.003)\end{array}$ & $\begin{array}{c}-0.0094 \\
(0.01)\end{array}$ & $\begin{array}{l}0.0025 \\
(0.008)\end{array}$ & $\begin{array}{l}0.0038 \\
(0.003)\end{array}$ \\
\hline Republican Fundraising Advantage & $\begin{array}{c}0.0075^{*} \\
(0.003)\end{array}$ & $\begin{array}{c}0.011 \\
(0.007)\end{array}$ & $\begin{array}{l}0.014 * \\
(0.003)\end{array}$ & $\begin{array}{l}0.021 \\
(0.01)\end{array}$ & $\begin{array}{c}-0.0018 \\
(0.002)\end{array}$ & $\begin{array}{l}0.0022 \\
(0.002)\end{array}$ \\
\hline Democratic Vote Top of the Ticket & $\begin{array}{c}-1.07 * \\
(0.005)\end{array}$ & $\begin{array}{l}-0.98 * \\
(0.02)\end{array}$ & $\begin{array}{c}-1.00^{*} \\
(0.008)\end{array}$ & $\begin{array}{c}-0.84^{*} \\
(0.04)\end{array}$ & $\begin{array}{c}-0.98 * \\
(0.02)\end{array}$ & $\begin{array}{c}-0.97^{*} \\
(0.01)\end{array}$ \\
\hline Mean of Outcome & 0.60 & 0.46 & 0.57 & 0.54 & 0.54 & 0.53 \\
\hline R-squared & 0.73 & 0.61 & 0.67 & 0.52 & 0.62 & 0.63 \\
\hline Clusters & 20 & 12 & 113 & 12 & 10 & 70 \\
\hline Observations & $4,114,796$ & 346,529 & $1,246,364$ & 238,949 & 369,369 & 333,860 \\
\hline
\end{tabular}

(b) Open-Seat Races (No Incumbent)

\begin{tabular}{lcccccc}
\hline & \multicolumn{5}{c}{ Outcome: Vote for Republican for } \\
\cline { 2 - 7 } & U.S. & $\begin{array}{c}\text { State } \\
\text { Souse }\end{array}$ & $\begin{array}{c}\text { State } \\
\text { Senate }\end{array}$ & $\begin{array}{c}\text { House } \\
\text { Sheriff }\end{array}$ & $\begin{array}{c}\text { Probate } \\
\text { Judge }\end{array}$ & $\begin{array}{c}\text { County } \\
\text { Council }\end{array}$ \\
\hline Republican Newspaper Coverage Advantage & -0.016 & 0.0037 & $-0.015^{*}$ & $-0.024^{*}$ & 0.0071 & 0.0086 \\
& $(0.010)$ & $(0.007)$ & $(0.007)$ & $(0.002)$ & $(0.006)$ & $(0.007)$ \\
& $0.010)^{*}$ & 0.0087 & $0.024^{*}$ & $0.21^{*}$ & 0.013 & 0.0015 \\
Republican Fundraising Advantage & $(0.003)$ & $(0.006)$ & $(0.006)$ & $(0.008)$ & $(0.03)$ & $(0.001)$ \\
& $-1.05^{*}$ & $-1.04 *$ & $-1.00^{*}$ & $-0.84^{*}$ & $-0.99 *$ & $-1.01 *$ \\
Democratic Vote Top of the Ticket & $(0.01)$ & $(0.01)$ & $(0.02)$ & $(0.10)$ & $(0.03)$ & $(0.01)$ \\
\hline Mean of Outcome & 0.60 & 0.48 & 0.55 & 0.53 & 0.53 & 0.51 \\
R-squared & 0.69 & 0.71 & 0.65 & 0.58 & 0.66 & 0.64 \\
Clusters & 6 & 7 & 30 & 6 & 9 & 27 \\
Observations & $1,204,029$ & 205,721 & 346,203 & 90,466 & 129,171 & 125,091 \\
\hline
\end{tabular}

Note: Each column is a regression from a linear probability model for one down-ballot office (equation (1)), but with all valence attributes in the same regression instead of one attribute at a time as in Figure 3. Standard errors clustered by district are in parentheses. Intercept and fixed effects for each election year not shown. "Democratic Vote Top of the Ticket" is the proportion of Democratic votes in the office of President, U.S. Senate, Governor, and the party lever, where applicable. Valence attributes are explained in the main text. ${ }^{*} p<0.05$ 
Table D7: Replication of Table D6 excluding Roll-off and Third Party Vote

(a) Contested Contests with an Incumbent

\begin{tabular}{|c|c|c|c|c|c|c|}
\hline & \multicolumn{6}{|c|}{ Outcome: Vote for Republican for } \\
\hline & $\begin{array}{l}\text { U.S. } \\
\text { House }\end{array}$ & $\begin{array}{c}\text { State } \\
\text { Senate }\end{array}$ & $\begin{array}{l}\text { State } \\
\text { House }\end{array}$ & Sheriff & $\begin{array}{c}\text { Probate } \\
\text { Judge }\end{array}$ & $\begin{array}{l}\text { County } \\
\text { Council }\end{array}$ \\
\hline Republican Incumbent & $\begin{array}{l}-0.027 \\
(0.02)\end{array}$ & $\begin{array}{l}0.12 * \\
(0.05)\end{array}$ & $\begin{array}{l}0.056^{*} \\
(0.02)\end{array}$ & $\begin{array}{l}0.26^{*} \\
(0.05)\end{array}$ & $\begin{array}{l}0.17 * \\
(0.03)\end{array}$ & $\begin{array}{l}0.042 * \\
(0.02)\end{array}$ \\
\hline Republican Newspaper Coverage Advantage & $\begin{array}{l}0.0051 \\
(0.004)\end{array}$ & $\begin{array}{l}-0.018 \\
(0.01)\end{array}$ & $\begin{array}{c}-0.0044 \\
(0.003)\end{array}$ & $\begin{array}{l}-0.010 \\
(0.01)\end{array}$ & $\begin{array}{c}0.00057 \\
(0.009)\end{array}$ & $\begin{array}{l}0.0042 \\
(0.003)\end{array}$ \\
\hline Republican Fundraising Advantage & $\begin{array}{c}0.0049^{*} \\
(0.001)\end{array}$ & $\begin{array}{c}0.013 \\
(0.008)\end{array}$ & $\begin{array}{l}0.013^{*} \\
(0.002)\end{array}$ & $\begin{array}{l}0.023 \\
(0.01)\end{array}$ & $\begin{array}{r}-0.0015 \\
(0.002)\end{array}$ & $\begin{array}{l}0.0023 \\
(0.002)\end{array}$ \\
\hline Democratic Vote Top of the Ticket & $\begin{array}{l}-1.08 * \\
(0.006)\end{array}$ & $\begin{array}{l}-0.99 * \\
(0.02)\end{array}$ & $\begin{array}{l}-1.01 * \\
(0.008)\end{array}$ & $\begin{array}{l}-0.85^{*} \\
(0.04)\end{array}$ & $\begin{array}{l}-0.98^{*} \\
(0.02)\end{array}$ & $\begin{array}{l}-0.98 * \\
(0.01)\end{array}$ \\
\hline $\begin{array}{l}\text { Mean of Outcome } \\
\text { R-squared } \\
\text { Clusters } \\
\text { Observations }\end{array}$ & $\begin{array}{c}0.62 \\
0.78 \\
20 \\
3,985,095\end{array}$ & $\begin{array}{c}0.47 \\
0.63 \\
12 \\
339,066\end{array}$ & $\begin{array}{c}0.58 \\
0.69 \\
113 \\
1,221,472\end{array}$ & $\begin{array}{c}0.55 \\
0.53 \\
12 \\
235,150\end{array}$ & $\begin{array}{c}0.55 \\
0.64 \\
10 \\
362,663\end{array}$ & $\begin{array}{c}0.55 \\
0.66 \\
70 \\
325,231\end{array}$ \\
\hline
\end{tabular}

(b) Open-Seat Races (No Incumbent)

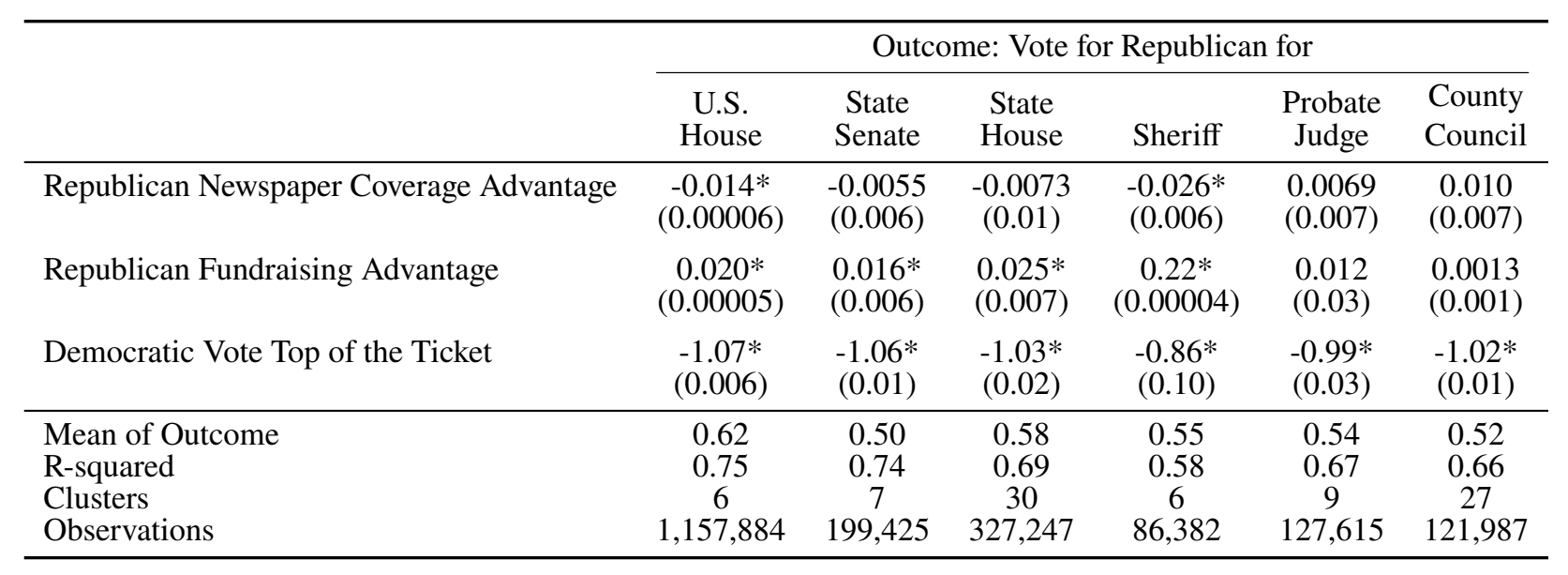

Note: See Table D6. 


\section{D.4 Overtime Change in Party Loyalty}

To track whether split ticket races are declining over the time of study, it was necessary to hold office constant. However, only certain pairs of offices have elections that occur simultaneously in the same election. Moreover, the changing ideology of candidates, rather than voters, could result in differences over time (Hall 2019). I therefore examine the same-party voting rates between the U.S. House and State House, which are up for election every two years.

Table D8 shows how the degree of co-partisan voting in the U.S. House and the State House has changed over time for four generals elections. Both specifications show a strong increasing trend of partisan allegiance at the house district level of about 2 to 3 percentage points every general election cycle. This pattern is consistent with what Rogers (2023) documents with aggregate voteshares. That analysis finds that the coefficient predicting State House votes with district Presidential vote (controlling for incumbency and party control) rose from 0.58 to 0.77 between 2010 and 2022. The same coefficient predicting the U.S. House changed from 0.73 to 0.95 in the same time period.

Table D8: Straight-Ticket Voting Overtime

\begin{tabular}{lcc}
\hline & $(1)$ & $(2)$ \\
\hline Time (2-Year Increment) & $0.032^{*}$ & $0.018^{*}$ \\
& $(0.009)$ & $(0.005)$ \\
Midterm Year & $0.050^{*}$ & $0.042^{*}$ \\
& $(0.02)$ & $(0.009)$ \\
Constant & $0.76^{*}$ & $0.80^{*}$ \\
& $(0.02)$ & $(0.010)$ \\
\hline Fixed Effects by & Congressional District & House District \\
Average of Outcome & 0.86 & 0.86 \\
Std. Dev. of Outcome & 0.11 & 0.11 \\
R-squared & 0.22 & 0.94 \\
Observations & 151 & 151 \\
\hline
\end{tabular}

Note: Each column is a linear regression with the pairwise straight-ticket rate between the U.S. House and State House in each State House district. The "time" variable is computed by (year - 2012) / 2, and thus its coefficient indicates the change in the rate in the next general election. Midterm year is a binary indicator. Standard errors in parentheses. ${ }^{*} p<0.05$. 


\section{Appendix E: Chustering Algorithm}

This appendix formalizes and derives the key steps of the clustering model and EM algorithm. The notation follows the main text. An open-source package, clusterCVR, implements these methods.

\section{E.1 Setup}

Index individuals by $i \in\{1, \ldots, N\}$ and the universe of races excluding the top of the ticket as $j \in\{1, \ldots, J\}$. The data we observe is $N$ sets of length- $J$ vector of votes for voter $i, \mathbf{Y}_{i} . Y_{i j}$ is a categorical response value, $Y_{i j} \in\{0, \ldots, L\}$.

$Y_{i j}$ is recoded with respect to the top of the ticket. In the simplest case $L=1, Y_{i j}$ is an indicator for a split ticket. $Y_{i j}=1$ would mean voter $i$ splitting their ticket in some office $j$, with reference to a top of the ticket office like the President or Governor. In the case of $L=2$, which will be our default setting, we can consider three outcomes: $Y_{i j}=0$ indicates roll-off / abstention, $Y_{i j}=1$ indicates ticket splitting and $Y_{i j}=2$ indicates straight (co-party) voting.

\section{E.1.1 Parameters}

There are two sets of parameters: $\boldsymbol{\mu}$, the propensity for a given outcome for a given type of voter in a given office; and $\pi$, the mixing proportions of each type. Individuals are endowed with a cluster (or type) $k \in\{1, \ldots, K\}$, which is drawn from a distribution governed by length- $K$ simplex $\pi$ (the mixing proportion).

$$
Z_{i} \sim \operatorname{Cat}(\pi)
$$

Here $\pi$ is the same for every individual, indicating that before we observe outcomes, everyone has the same probabilty of being in a particular cluster. If individual demographic covariates are available, these can be incorporated to make the prior probability more granular.

Let $\mu_{k j \ell} \in[0,1]$ be the probability parameter that governs the probability of a given outcome for a given office, by a given type of voter. That is, $\boldsymbol{\mu}$ is a $\{K \times J \times(L+1)\}$ array, where

$$
\operatorname{Pr}\left(Y_{i j}=\ell \mid Z_{i}=k\right)=\mu_{k j \ell}
$$

In other words, for each individual (who is type $k$ ), their observed vector $\mathbf{Y}_{i}$ is governed by a length- $J$ parameter $\boldsymbol{\mu}_{k}$. Therefore, we can express the joint density as follows.

$$
\operatorname{Pr}\left(\mathbf{Y}_{i} \mid Z_{i}=k, \boldsymbol{\pi}\right)=\prod_{j=1}^{J} \operatorname{Cat}\left(Y_{i j} \mid \boldsymbol{\mu}_{k}\right)=\prod_{j=1}^{J} \prod_{\ell=0}^{L} \mu_{k j \ell}^{\mathbf{1}\left(Y_{i j}=\ell\right)}
$$


The loop over $\ell$ simply represents the categorical distribution. In the binary case of $L=1$, the Categorical reduces to a Bernoulli:

$$
\operatorname{Pr}\left(\mathbf{Y}_{i} \mid Z_{i}=k, \boldsymbol{\pi}\right)=\prod_{j=1}^{J} \mu_{k j}^{Y_{i j}}\left(1-\mu_{k j}\right)^{1-Y_{i j}}
$$

\section{E.2 EM Algorithm, Fully Contested Case}

The common way to estimate mixture models is by using $K$-means, an iterative but deterministic algorithm. The usual MCMC sampler cannot reliably estimate clustering models like this one because of label-switching and multimodality. Moreover, the majority of existing clustering methods are dealt to model continuous or binary outcomes.

Instead, here I derive an Expectation Maximization (EM) algorithm, which is probabilistic and guaranteed to recover the (local) maximum likelihood estimates of the target parameters. Unlike off-the-shelf algorithms, this can handle extensions such as discrete and unordered multinomial outcomes, systematic missing data, and covariates. The rest of this paper outlines the EM algorithm.

\section{E.2.1 Complete Likelihood}

If we knew the cluster assignment, we would be able to write the complete log-likelihood ( $\left.\mathcal{L}_{\text {comp }}\right)$. First start with the joint probability of the outcome data and the cluster assignment:

$$
\begin{aligned}
\operatorname{Pr}(\mathbf{Y}, \mathbf{Z} \mid \boldsymbol{\mu}, \boldsymbol{\pi}) & =\operatorname{Pr}(\mathbf{Y} \mid \mathbf{Z}, \boldsymbol{\mu}, \boldsymbol{\pi}) \operatorname{Pr}(\mathbf{Z} \mid \boldsymbol{\pi}) \\
& =\prod_{i=1}^{N} \prod_{j=1}^{J} \operatorname{Pr}\left(Y_{i j} \mid \mathbf{Z}, \boldsymbol{\mu}\right) \prod_{i=1}^{N} \operatorname{Pr}\left(Z_{i} \mid \boldsymbol{\pi}\right) \\
& =\prod_{i=1}^{N} \prod_{j=1}^{J} \prod_{k=1}^{K}\left\{\prod_{\ell=0}^{L} \operatorname{Pr}\left(Y_{i j}=\ell \mid Z_{i}=k\right)^{\mathbf{1}\left(Y_{i j}=\ell\right)}\right\}^{\mathbf{1}\left(Z_{i}=k\right)} \prod_{i=1}^{N} \prod_{k=1}^{K} \operatorname{Pr}\left(Z_{i}=k \mid \boldsymbol{\pi}\right)^{\mathbf{1}\left(Z_{i}=k\right)}
\end{aligned}
$$

Therefore, the complete log-likelihood is:

$$
\begin{gathered}
\mathcal{L}_{\text {comp }}(\boldsymbol{\mu}, \boldsymbol{\pi} \mid \mathbf{Y}, \mathbf{Z})=\sum_{i=1}^{N} \sum_{j=1}^{J} \sum_{k=1}^{K} \sum_{\ell=0}^{L} 1\left\{Y_{i j}=\ell, Z_{i}=k\right\} \log \operatorname{Pr}\left(Y_{i j}=\ell \mid Z_{i}=k, \boldsymbol{\mu}\right) \\
+\sum_{i=1}^{N} \sum_{k=1}^{K} 1\left\{Z_{i}=k\right\} \log \operatorname{Pr}\left(Z_{i}=k \mid \boldsymbol{\pi}\right)
\end{gathered}
$$


To derive the EM algorithm, first take expectations over the latent variable $Z_{i}$,

$$
\begin{aligned}
\mathbb{E}\left[\mathcal{L}_{\text {comp }}\right]=\sum_{i=1}^{N} & \sum_{j=1}^{J} \sum_{k=1}^{K} \sum_{\ell=0}^{L} \mathbf{1}\left(Y_{i j}=\ell\right) \mathbb{E}\left[\mathbf{1}\left(Z_{i}=k\right)\right] \underbrace{\log \operatorname{Pr}\left(Y_{i j}=\ell \mid Z_{i}=k, \boldsymbol{\mu}\right)}_{\equiv \log \mu_{k j \ell}} \\
& +\sum_{i=1}^{N} \sum_{k=1}^{K} \mathbb{E}\left[1\left(Z_{i}=k\right)\right] \underbrace{\log \operatorname{Pr}\left(Z_{i}=k \mid \boldsymbol{\pi}\right)}_{=\log \pi_{k}}
\end{aligned}
$$

We represent this unknown quantity as

$$
\zeta_{i k} \equiv \mathbb{E}\left[1\left(Z_{i}=k\right)\right]
$$

Then the E-step can be the normalized version of the posterior probability marginalized by the mixing proportion,

$$
\widehat{\zeta}_{i k} \propto \pi_{k} \prod_{j=1}^{D} \underbrace{\prod_{\ell=0}^{L}\left(\mu_{k j \ell}\right)^{\mathbf{1}\left(Y_{i j}=\ell\right)}}_{\equiv \boldsymbol{\mu}_{k j, Y_{i j}}}
$$

E-step For each voter $i$, compute the probability that they belong in cluster $k$ :

$$
\zeta_{i k} \leftarrow \frac{\boldsymbol{\pi}_{k} \prod_{j=1}^{J} \boldsymbol{\mu}_{k j, Y_{i j}}}{\sum_{k^{\prime}=1}^{K} \boldsymbol{\pi}_{k^{\prime}} \prod_{j=1}^{J} \boldsymbol{\mu}_{k^{\prime} j, Y_{i j}}}
$$

The M-step is derived by taking the derivatives of $\mathbb{E}\left[\mathcal{L}_{\text {comp }}\right]$ with respect to the model parameters $\boldsymbol{\mu}$ and $\boldsymbol{\pi}$. This leads to a MLE-like M-step:

M-step Take the MLE as follows: For updating $\pi_{k}$, take the simple average of $\widehat{\zeta}_{i k}$ across all $i$. For updating $\widehat{\mu}_{k j \ell}$, take for each $k$ and $\ell$ the sample proportion of the occurrence of $Y_{i j}=\ell$, but weighted by $\widehat{\zeta}_{i k}$. That is,

$$
\begin{aligned}
\text { for each } k \text {, update: } \widehat{\pi}_{k} \leftarrow \frac{1}{N} \sum_{i=1}^{N} \widehat{\zeta}_{i k} \\
\text { for each } k, j, \ell, \text { update: } \quad \widehat{\mu}_{k j \ell} \leftarrow \frac{\sum_{i=1}^{N} 1\left(Y_{i j}=\ell\right) \widehat{\zeta}_{i k}}{\sum_{i=1}^{N} \widehat{\zeta}_{i k}},
\end{aligned}
$$

We iterate through these two steps until convergence. 


\section{E.2.2 Evaluating Convergence}

We evaluate convergence by the observed likelihood,

$$
\mathbf{L}_{\mathrm{obs}}=\prod_{i=1}^{N} \sum_{k=1}^{K} \pi_{k} \prod_{j=1}^{J} \boldsymbol{\mu}_{k j, Y_{i j}}
$$

The $\log$ of which is

$$
\mathcal{L}_{\mathrm{obs}}=\sum_{i=1}^{N} \log \left\{\sum_{k=1}^{K} \pi_{k} \prod_{j=1}^{J} \boldsymbol{\mu}_{k j, Y_{i j}}\right\}=\sum_{i=1}^{N} \log \left\{\sum_{k=1}^{K} \pi_{k} \prod_{j=1}^{J} \prod_{\ell=0}^{L}\left(\mu_{k j \ell}\right)^{\mathbf{1}\left(Y_{i j}=\ell\right)}\right\} .
$$

\section{E.3 Modeling Uncontested Races}

A majority of elections for state and local offices are uncontested, which means that a voter technically votes in a choice but cannot vote for one of the parties. In other words, the choice sets vary between a contested case and an uncontested case. In typical clustering algorithms, varying choice sets are dropped with listwise deletion. Here, I account for varying choice sets.

\section{E.3.1 Categories of uncontestedness}

In uncontested races, some options are not available to choose from. To show this, I introduce a new layer of notation: voter $i$ for a given office $j$ is in one of three settings, denoted by $M_{i j} \in\{1,2,3\}$. Unlike the cluster $Z_{i}$, the status of $M_{i j}$ is exactly observed in the data.

Denote $M_{i j}=3$ to mean vote $j$ for voter $i$ falls in the contested case, so the voter has all three options on the "menu". Denote $M_{i j}=2$ as the case when only the preferred party's candidate is in the contest, so the voter only has options $Y_{i j} \in\{0,2\}$. Finally denote $M_{i j}=1$ as the case when only the opposed party's candidate is in the contest, so the voter only has the option to abstain or reluctantly (perhaps) vote for the less favored option by splitting: $Y_{i} \in\{0,1\}$. For shorthand, I use the notation $S_{m}$ for the set of possible of values of $Y_{i j}$ allowed for a given category of contestedness:

$$
S_{m}= \begin{cases}\{0,1\} & \text { if } m=1 \\ \{0,2\} & \text { if } m=2 \\ \{0,1,2\} & \text { if } m=3\end{cases}
$$

Therefore the complete likelihood is modified by replacing the loop $\ell=\{0, \ldots, L\}$ to $\ell \in S_{m}$. 


\section{E.3.2 Shared Parameters across Varying Choice Sets}

To express the choice probability for option $\ell$ for office $j$ among voters of type $k$, let us introduce another parameter $\boldsymbol{\psi}$ which represents the intensity of preference for option $\ell \in\{1,2\}$ relative to $\ell=0$ (abstention). We set the baseline for abstention to be 0 , i.e. $\psi_{k j,(\ell=0)}=0 \forall k, j$.

In the simplest case where clusters are completely homogenous, we paramterize our main variable of interest $\boldsymbol{\mu}$ as follows, while remembering that each individual is a member of type $\left(Z_{i}\right)$ and each separate office is also of a missingness type $M_{i j}$.

$$
\mu_{k j \ell}=\frac{1}{N \pi_{k}} \sum_{i=1}^{N} \mathbf{1}\left(Z_{i}=k, M_{i j}=m\right) \frac{\exp \left(\psi_{k j \ell}\right)}{\sum_{\ell^{\prime} \in S_{m}} \exp \left(\psi_{k j \ell^{\prime}}\right)}
$$

Analog to Multinomial Logit Because $\exp \left(\psi_{k j \ell}\right)=1$ for $\ell=0$, which exists in all three components, each component is analogous to a simple multinomial logit. In the first two cases, since we consider only two possibilities, it reduces to a simple intercept-only logit. Also notice that we use the same set of parameters $\psi_{k j}$ regardless of $M_{i j}$. This represents the well-known independence of irrelevant alternatives (IIA) assumption in multinomial logit. The choice probabilities when one option is not on the "menu" is assumed to follow the same type of decision rule as the ratio between the existing options.

\section{E.3.3 EM Estimation of Varying Choice Sets}

M-step We use this new representation of the parameter $\mu$ in the EM algorithm, replacing the weighted average M-step for $\mu$ with a weighted multinomial logit:

$$
\begin{aligned}
\text { for each } k \text {, update: } \quad \widehat{\pi}_{k} \leftarrow \frac{1}{N} \sum_{i=1}^{N} \widehat{\zeta}_{i k} \\
\text { for each } k, j, \ell \text {, update: } \quad \widehat{\mu}_{k j \ell} \leftarrow \frac{\exp \left(\widehat{\psi}_{k j \ell}\right)}{1+\exp \left(\widehat{\psi}_{k j 1}\right)+\exp \left(\widehat{\psi}_{k j 2}\right)},
\end{aligned}
$$

where the $\psi_{k j}$ vector is estimated from the coefficients of a multinomial logit, of the form

$$
\operatorname{mlogit}(Y[j]] \sim 1 \text {, data, weights }=\text { zeta_k })
$$

In other words, for each $k, j$, we estimate intercepts from regressing a vector of categorical votes for office $\mathbf{Y}_{j}$, using the estimates of $\boldsymbol{\zeta}_{k}$ as the weight zeta_k. R packages of multinomial logit typically presume IIA if an outcome value is missing and implicitly do the kind of three-way subsetting as in equation (14). 


\section{E.3.4 Evaluating Convergence with varying choice sets}

When following the EM algorithm on this data affected by uncontested choices, the observed log likelihood changes. Recall that in the no-missing case, we have equation (13). However, in cases of varying choice sets, the contribution of a data point also depends on the contestedness class.

Therefore, convergence is evaluated on the following log likelihood, where we modify (13) to evaluate among only the contested class of each voter and office:

$$
\mathcal{L}_{\mathrm{obs}}^{\star}=\sum_{i=1}^{N} \log \left[\sum_{k=1}^{K} \pi_{k} \prod_{j=1}^{J} \prod_{\ell \in S_{M_{i j}}}\left\{\left(\frac{\mu_{k j \ell}}{\sum_{\ell^{\prime} \in S_{M_{i j}}} \mu_{k j \ell^{\prime}}}\right)^{\mathbf{1}\left(Y_{i j}=\ell\right)}\right\}\right] .
$$

\section{E.4 Selection of the Number of Clusters}

Figure E8 shows the change in the model fit statistic for varying numbers of clusters modeled. The statistic used is the Bayesian Information Criterion (BIC) defined in Fraley and Raftery (1998). For a given choice of $K$,

$$
\mathrm{BIC}_{K}=2 \widehat{\mathcal{L}}-\log (K+J K L) \log (N)
$$

where $\widehat{\mathcal{L}}$ is the observed $\log$ likelihood with the estimated parameters, $J$ is the number of offices, $L$ is the number of choices in a given race, and $N$ is the number of voters. In this application, $K+J K L$ amounts to the number of parameters estimated. Higher numbers indicate better fit, with a penalty for too many parameters. 
Figure E8: Model Fit by Number of Clusters. The Bayesian Information Criterion (BIC) scaled by the number of voters in each subroup. Higher values indicated better overall mode fit accounting for overfitting. The first panel analyzes 2012 voters, and the second panel analyzes 2016 voters. The line is the value of $K$ where the improvement in the BIC roughly starts to plateau.
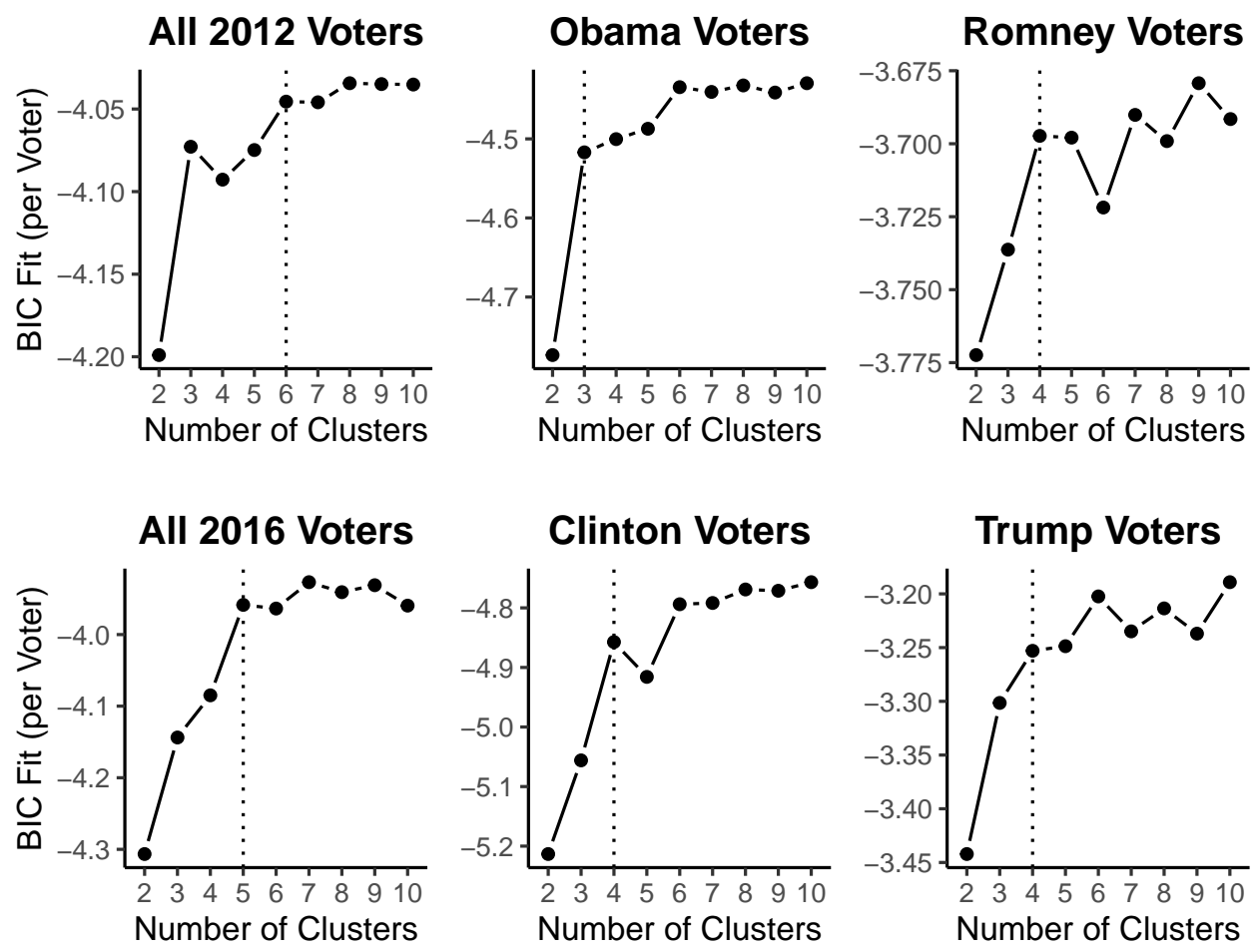


\section{REFERENCES FOR APPENDix}

Aldrich, John H. 2000. "Presidential Address: Southern Parties in State and Nation." The Journal of Politics 62 (3): 643-670.

Ansolabehere, Stephen, and James M. Snyder. 2000. "Valence Politics and Equilibrium in Spatial Election Models." Public Choice 103 (3): 327-336.

Fraley, Chirs, and Adrian E. Raftery. 1998. "How Many Clusters? Which Clustering Method? Answers Via Model-Based Cluster Analysis.” The Computer Journal 41 (8): 578-588.

Groseclose, Tim. 2007. "A Model of Candidate Location When One Candidate Has a Valence Advantage.” American Journal of Political Science 45 (4): 862-886.

Hall, Andrew B. 2019. Who Wants to Run?: How the devaluing of political office drives polarization. University of Chicago Press.

Herron, Michael C., and Jeffrey B. Lewis. 2007. "Did Ralph Nader Spoil a Gore presidency? A Ballot-level Study of Green and Reform Party Voters in the 2000 Presidential Election." Quarterly Journal of Political Science 2 (3): 205-226.

Klarner, Carl. 2021. State Legislative Election Returns, 1967-2018, Version 120.

Lublin, David. 2007. The Republican South: Democratization and Partisan Change. Princeton University Press.

Rogers, Steven. 2023. “The Vanishing Incumbency Advantage in State House Elections.” The Forum. 